University of Louisville

ThinkIR: The University of Louisville's Institutional Repository

$12-2011$

\title{
The development of deviant behavior in adolescents : the influence of student characteristics and school climate.
}

Jessica Damron-Bell

University of Louisville

Follow this and additional works at: https://ir.library.louisville.edu/etd

\section{Recommended Citation}

Damron-Bell, Jessica, "The development of deviant behavior in adolescents : the influence of student characteristics and school climate." (2011). Electronic Theses and Dissertations. Paper 309.

https://doi.org/10.18297/etd/309

This Doctoral Dissertation is brought to you for free and open access by ThinkIR: The University of Louisville's Institutional Repository. It has been accepted for inclusion in Electronic Theses and Dissertations by an authorized administrator of ThinkIR: The University of Louisville's Institutional Repository. This title appears here courtesy of the author, who has retained all other copyrights. For more information, please contact thinkir@louisville.edu. 
THE DEVELOPMENT OF DEVIANT BEHAVIOR IN ADOLESCENTS:

THE INFLUENCE OF STUDENT CHARACTERISTICS AND SCHOOL CLIMATE

By

Jessica Damron-Bell

B.A., University of Kentucky, 2002

M.S., Eastern Kentucky University, 2004

\author{
A Dissertation \\ Submitted to the Faculty of the \\ Department of Educational and Counseling Psychology of the \\ University of Louisville \\ in Partial Fulfillment of the Requirements \\ for the Degree of \\ Doctor of Philosophy \\ Department of Educational and Counseling Psychology \\ University of Louisville \\ Louisville, Kentucky
}

December 2011 
THE DEVELOPMENT OF DEVIANT BEHAVIOR IN ADOLESCENTS:

THE INFLUENCE OF STUDENT CHARACTERISTICS AND SCHOOL CLIMATE

By

Jessica Damron-Bell

B.A., University of Kentucky, 2002

M.S., Eastern Kentucky University, 2004

A Dissertation Approved on

November 3, 2011

By the following Dissertation Committee:

Sam Stringfield, Dissertation Chair

Kathy Rudasill

Linda Shapiro

Jesse Owen 


\section{ACKNOWLEDGMENTS}

I would like to thank my chair, Dr. Sam Stringfield, and Dr. Kathy Rudasill, for the tremendous amount of support and guidance they have provided me in completing this dissertation, as well as my other committee members, Dr. Jesse Owen and Dr. Linda Shapiro. These individuals went above and beyond in every way to support me, and I am forever grateful.

I would also like to thank Dr. Nate Mitchell for his constant support and encouragement throughout this process and especially his guidance with statistics. I am also grateful to Dr. Susan Brittain for her continual friendship and support throughout this process.

To my family, my wonderful husband, Travis Bell whose understanding and patience has endured throughout this journey, my son, Cameron who works on his "dissertation" along with me, my son, Aidan who brings me joy daily, and, my parents, Sandy and Richard Damron who have supported me from the beginning and instilled in me the perseverance and determination to succeed: there are not words adequate to express my thanks to you for helping me along every step of this journey. You have been there to encourage me through difficulties as well as to celebrate my successes, and I love you and am so grateful. 


\begin{abstract}
THE DEVELOPMENT OF DEVIANT BEHAVIOR IN ADOLESCENTS:

THE INFLUENCE OF STUDENT CHARACTERISTICS AND SCHOOL CLIMATE

Jessica Damron-Bell
\end{abstract}

November 3, 2011

This dissertation is an investigation of the influence of individual characteristics and school climate on the participation in deviant behaviors. The literature review provides a review of adolescent development and theories that guide the understanding of the different social and environmental factors that influence an adolescent's participation in deviant behavior. Additionally, the impact of adolescent participation in deviant behavior will be reviewed.

Using data gathered from Middle and High School students who completed surveys administered by a large, Midwestern, urban school district, the influence of gender, ethnicity, age, school level free/reduced lunch status, school level performance on standardized testing, and school level perception of school climate on the participation in risky behaviors were examined. For the purpose of this study, 2 different samples were used. The first sample included 15,299 Middle School students and16,390 High School students. For the second sample, the student reported data was aggregated to the school level representing each of 42 schools. One multiple regression was used to examine the extent to which student level data of gender, ethnicity, and age predicted student participation in risky behaviors. Another multiple regression examined the extent 
to which student data aggregated to the school level of school level status (middle or high school), school level perception of school climate, school performance on standardized testing, and free/reduced lunch status predicted students' self report of risky behaviors.

Results reflected that gender, ethnicity, and age were significant predictors of participation in risky behaviors such that males more frequently participated in risky behaviors than females, whites more frequently participated in risky behaviors than racial and ethnic minorities, and older students more frequently participated in risky behaviors than younger students. Regarding results at the school level, student data aggregated to the school level of school level status (middle or high school), school level perception of school climate, school performance on standardized testing, and free/reduced lunch status predicted students' self report of risky behaviors, these results were mixed. School level status was shown to be the only significant predictor of participation in risky behaviors. However, because of high correlations between the free/reduced lunch status and standardized test scores variables a second set of analyses was conducted in which standardized test scores were removed. This regression equation reflected that school level status and school climate were significant predictors of participation in risky behaviors. These results are consistent with prior research. 


\section{TABLE OF CONTENTS}

PAGE





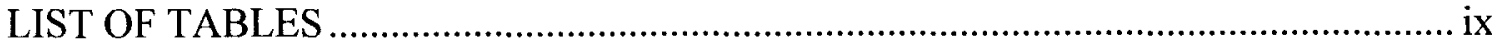

\section{CHAPTER}

I. INTRODUCTION 1

Purpose of the Study ........................................................................................ 1

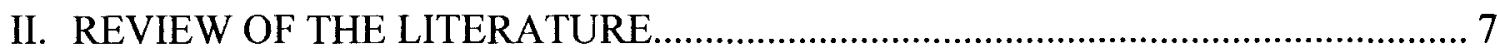

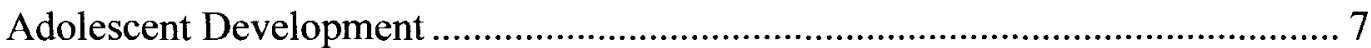

Bronfenbrenner's Model of the Ecology of Human Development .............9

Social Learning Theory ..............................................11

Hirschi's Social Control Theory.......................................12

Student Characteristics and Deviant Behavior ..................................................... 15

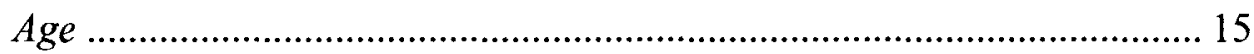

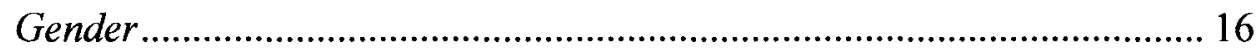

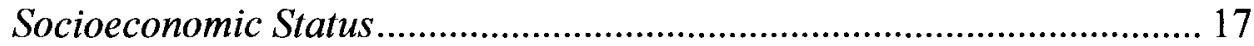

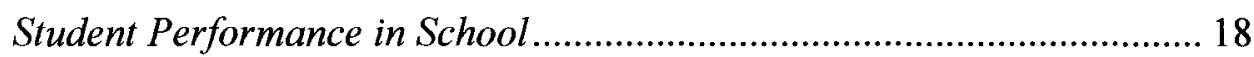

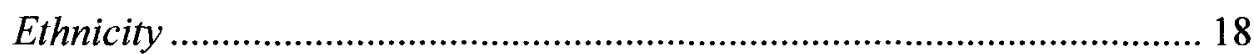

Influences on the Development of Deviant Behavior ............................................ 20

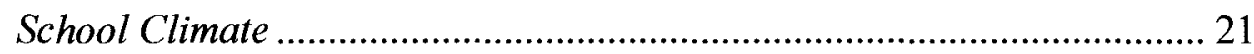

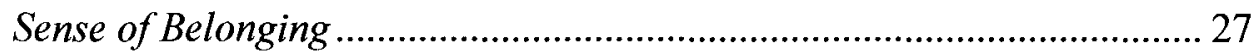


Protective Factors ................................................................................. 32

Engagement in Deviant Behavior and its Effects ...............................................36

Research Questions and Hypotheses ................................................................. 39

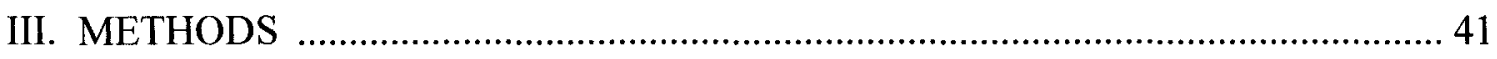

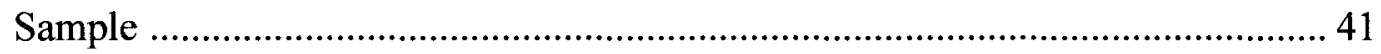

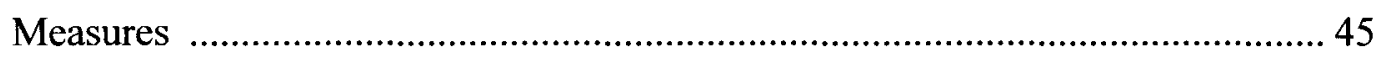

The Comprehensive Schools Survey .......................................................... 45

School Support Survey (Middle School and High School) ........................ 46

The Safe \& Drug Free Schools Survey ...................................................... 48

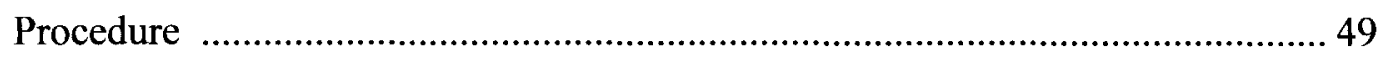

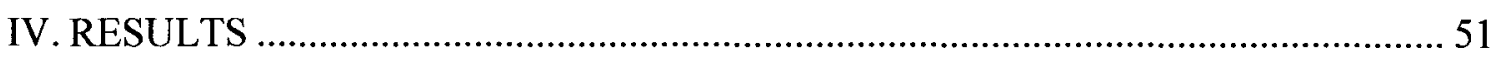

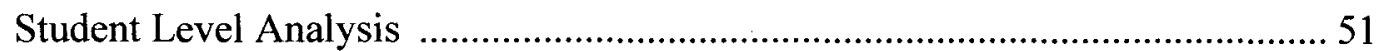

Risky Behavior as it Relates to Student Level Gender, Ethnicity, and Age

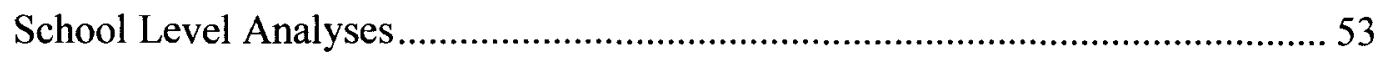

Risky Behavior as it Relates to Student Data Aggregated to the School

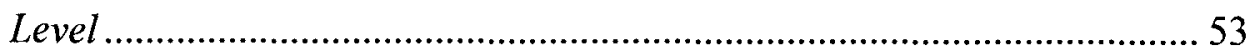

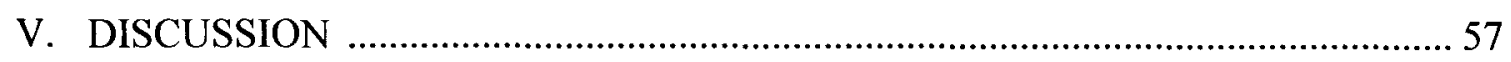

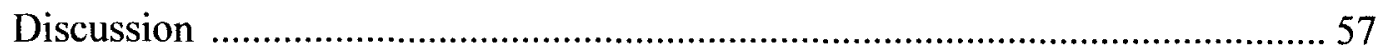



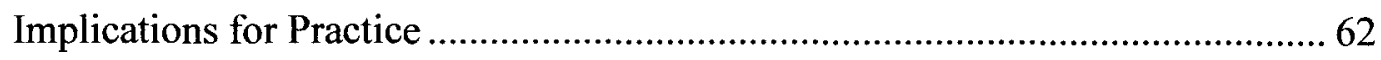






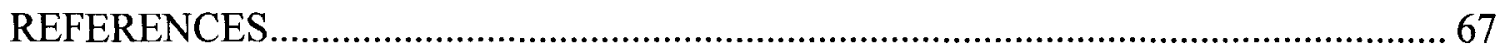

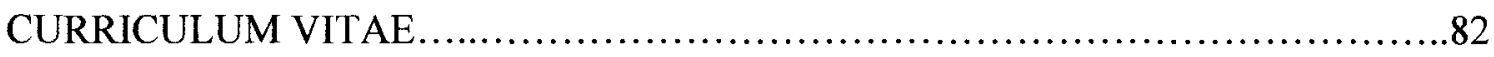




\section{LIST OF TABLES}

\section{TABLE}

1. Middle School Participants' Socio-Demographic Information, 2007-2008 school year

2. High School Participants' Socio-Demographic Information, 2007-2008 school year

3. Middle School: School Level Data for the 2007-2008 school year.

4. Middle Schools, School Support Items...........................................53

5. High School, School Support Items.........................................55

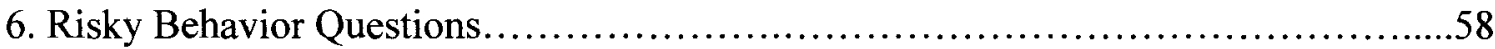

7. Linear Regression Predicting Risky Behaviors from Age, Gender, and Ethnicity.....61

8. Correlations Among Student Level Data: Age, Gender, Ethnicity, and Risky

Behaviors.

9. Linear Regression Predicting Risk Behaviors from School Level Status, School

Climate, Performance on Standardized tEsting and Free-Reduced Lunch Status.......62

10. Correlations Among School Level Data and Risk Behaviors .....................63

11. Linear Regression Predicting Risk Behaviors from Age, School Climate, and Free/Reduced Lunch Status..............................................65

12. Correlations Among School Level Data and Risk Behaviors ....................66 


\section{CHAPTER I}

\section{INTRODUCTION}

The primary purpose of this study was to examine the extent to which the student characteristics of age, gender, socioeconomic status, student performance in school, and ethnicity, as well as student perceptions of school climate contribute to the participation in risky behaviors. The goal of this dissertation was to build upon existing literature linking student characteristics (i.e., age, gender, socioeconomic status, student performance in school, and ethnicity) as well as student perceptions of school climate to adolescent participation in risky behaviors.

Adolescence has been described as a time of storm and stress to illustrate that it is a particularly difficult period for the adolescent as well as for those around them. This difficulty has been shown in various areas of the adolescent's life. For example, adolescents begin to resist adult authority and show more rebellion at this time. They also begin to exhibit more volatile emotions than they did as children and an increase in mood swings. Of great concern, adolescents have higher rates of reckless, normbreaking, and antisocial behavior than either children or adults (Arnett, 1999).

The transition to adolescence presents a variety of changes pertaining to one's cognitive, physical, and social development. With these changes the adolescent begins to make important decisions that have the potential for substantial impact on the adolescent's life (Harris, Duncan, \& Boisjoly, 2002). As the potential for engagement in 
behaviors defined as deviant, delinquent, and/or risky increase, the adolescent also has an increase in the severity of consequences for the choices made (Hirschi, 2002).

Because the participation in deviant behaviors (behaviors that are considered to be unacceptable and often illegal such as the use of alcohol and other drugs and engagement in risky driving) can hold severe consequences for the adolescent and because these behaviors have important implications for society, it is necessary to understand what contributes to and what potentially mediates the decisions to participate in deviant behavior.

There are number of individual characteristics that have been shown to contribute to differences among adolescents in regards to their participation in deviant behavior. These individual characteristics include age, gender, socioeconomic status, student performance in school, and ethnicity. There have also been many hypotheses as to what contributes to an adolescent's engagement in deviant behavior. The most common hypotheses focus on the social and environmental factors such as family, peers, school, community, and cultural belief systems that contribute to participation in deviant behavior (Harris, Duncan, \& Boisjoly, 2002).

Several theorists have presented models to help explain the social and environmental factors that contribute to the development of deviant behavior. The theories of ecology of human development (Bronfenbrenner, 1979), social learning (Akers, Krohn, Lanza-Kaduce, \& Radosevich, 1979; Bandura, 1977), and social control (Hirschi, 1969) are particularly relevant in the examination of the participation in deviant behavior in adolescence. These models give a conceptual framework for a better understanding of how individual characteristics, as well as, social and environmental 
aspects such as family, peers, schools, and communities contribute to the decisions an adolescent makes regarding participation in deviant behavior.

Bronfenbrenner's theory of the ecology of human development explains how different contexts contribute to the development of an adolescent (Bronfenbrenner, 1979). His model focuses on the interaction of an individual with his or her environment, as well as, on the settings within which development occurs and the interactions of the individual within and across those settings (Bronfenbrenner, 1989). An individual's settings start with the most immediate setting (family) and expand to include the influences of the individual's culture.

Social learning theory (Akers, 1977; Bandura, 1977) focuses on exposure to role models behavior and suggests that behavior is directly determined by specific environmental influences. Bandura $(1982,1986)$ further developed the model to include the constructs of outcome expectations and self-efficacy. Outcome expectations are the individual's beliefs about the consequences of engaging in the observed behavior of the role model. The role model also helps shape the individual's self efficacy in that if the individual observes the role model perform and succeed at the behavior this increases the individual's confidence in performing the behavior (Flay, Hu, Siddiqui, Day, Hedeker, Petraitis, Richardson, \& Sussman, 1994).

The last model that will be discussed in this dissertation is Hirschi's Social Control Theory (1969). Hirschi suggests that deviance has the opportunity to manifest when the bond between an individual and society is weakened. He further asserts that the potential for delinquency is present in every individual and the individual who does not commit delinquent acts was somehow prevented from doing so. Hirschi proposes that an 
individual's ability to refrain from engaging in a delinquent act has been encouraged by training and is maintained by the individual's connection to other people (peers, family) and institutions (schools) (Hirschi, 2002). To further distinguish between the individual who chooses to participate in the delinquent act and the individual who does not, he proposes that the individual who chooses not to participate can better control his or her natural motives (Hirschi, 2002).

As illustrated in the aforementioned theories, there are individual characteristics that are suggested to influence the choice to participate in or refrain from deviant behavior. For the purpose of this study, the characteristics of age, gender, socioeconomic status, student performance in school, and ethnicity are examined. Additionally, social contexts and their contribution to an individual's participation in deviant behavior are examined. Specifically, the influences of an individual's school climate, sense of belonging to school and peer relationships are explored.

Schools are often viewed as an important context for the development of adolescent behavior because adolescents spend much of their time in school. School climate is an aspect of the school context that includes the attitudes, beliefs, values, and norms that underlie the operation of a school (LaRusso, Romer, \& Selman, 2008). A student's sense of belonging is a salient part of the overarching construct of school climate and specifically refers to the extent to which a student feels personally accepted, included, and supported in the school (Ma, 2003).

An individual's relationship with his or her peers also has the potential for significant influence. As adolescents begin to focus their attention on relationships outside of the family during early adolescence they begin to rely more on peers as 
influences and less on their parents (LaRusso, Romer, \& Selmer, 2008). On average, adolescents spend approximately $50 \%$ of their time with their peers and $20 \%$ with their parents. Therefore it is important that there is understanding of how an adolescent's peers negatively and positively impact the adolescent's decision-making. It has been suggested that positive social relationships among students have the potential to influence school climate and further that the interaction of school structure and peer influence can interact to affect students' sense of belonging to school (Stockard \& Mayberry, 1992, Kester, 1994). In regards to the negative impact of peer relationships, it is also purported that adolescent's use of alcohol and drugs is done in the company of their peers (Zimring, 1998; Gardner \& Steinberg, 2005).

The discrepancy between those individuals participating in and refraining from deviant behavior can be attributed to a number of factors. This study further explores those factors and takes a closer look at what helps to prevent individuals from participating in deviant behaviors.

The hypotheses of this study are as follows. The first hypothesis addresses data gathered at the student level: gender, ethnicity, and age, will be significant predictors of students' self report of risky behavior such that males, Caucasians, and older adolescents will show greater self-reported participation in risky behavior.

The second hypothesis addresses student data aggregated to the school level. Hypothesis number two predicts that age (middle vs. high school), free/reduced lunch status, school performance on standardized testing, and school-level perception of school climate will be significant predictors of students' self report of risky behaviors. Specifically, student bodies in high schools, schools with majority free/reduced lunch 
status, schools with lower scores on standardized testing, and schools in which students report holding less positive perceptions of school climate will show greater student participation in risky behaviors. 


\section{CHAPTER II}

\section{REVIEW OF THE LITERATURE}

This chapter presents a review of the literature of adolescent development as it relates to participation in deviant, delinquent, and/or risky behavior. In this chapter the term deviant behavior includes but is not limited to risky driving and substance use.

Multiple theorists have attempted to explain the various factors, social and environmental, that contribute to the development of deviant behavior. The theories of ecology of human development, (Bronfenbrenner, 1979), social learning (Akers, Krohn, Lanza-Kaduce, \& Radosevich, 1979, Bandura, 1977), and social control (Hirschi, 1969), are used in this chapter to examine the development of deviant behavior in adolescence. Each theory provides a context for our understanding of how individual characteristics (i.e., age, gender, socioeconomic status, student performance, and ethnicity) interact with an individual's environment (schools, community, peers, and families) to contribute to the development of deviant behavior. This chapter will also provide a brief discussion of mediating factors which buffer or decrease risk of participation in deviant behavior. Finally, this chapter will provide a brief description of the immediate and long-term effects of engagement in risky/deviant behaviors on an adolescent.

\section{Adolescent Development}

The beginning of adolescence marks a difficult transition in which the adolescent may be particularly vulnerable to environmental influences promoting participation in 
deviant behavior. In this document, deviant behavior is used to describe a number of behaviors in adolescence that are considered to be unacceptable and sometimes illegal (delinquent behaviors). For the purpose of this study substance use and risky driving behaviors will be examined.

The tendency of delinquency to increase rapidly in early adolescence is clearly established (Arnett, 1999; Hirschi, 2002). Adolescents engage in risky behavior more frequently than adults (Jessor \& Jessor, 1977). Furthermore, adolescents experience the negative consequences of the delinquent behavior at a higher degree than adults (Harris, Duncan, \& Boisjoly, 2002). Adolescence delinquency increases from early to midadolescence and declines sharply by late adolescence (Harris, Duncan, \& Boisjoly, 2002).

Adolescence is a time in which an individual experiences physical and cognitive change and begins to make important decisions (Harris, Duncan, \& Boisjoly, 2002). These growing demands on decision-making have important implications for the engagement in risky behaviors. Clearly, adolescence is a time of choices. With these choices adolescents gain autonomy, assume responsibility, and face serious consequences regarding the decisions they make. For example, choices regarding the use of illegal substances and participation in risky driving behavior can have significant implications.

There have been many hypotheses as to why adolescents engage in risk taking behaviors. Some hypothesize that adolescents engage in deviant behaviors to demonstrate maturity or mark the transition to adulthood (Jessor, 1987). Others postulate that the behavior results from heightened egocentrism and a desire for sensation seeking (Elkind, 1985). However, most believe that deviant behavior is a result of social and environmental factors such as family, peers, school, community, and cultural belief 
systems (Harris, Duncan, \& Boisjoly, 2002). Adolescents interact at the same time in several social systems - such as family, peer, and neighborhood systems - that can serve to either restrain or promote individual behaviors.

Several theorists have attempted to explain the various factors, social and environmental, that contribute to the development of deviant behavior. In this chapter, the theories of ecology of human development, (Bronfenbrenner, 1979), social learning (Akers, Krohn, Lanza-Kaduce, \& Radosevich, 1979; Bandura, 1977), and social control (Hirschi, 1969) are used to examine the development of deviant behavior in adolescence. These models give a framework to understand the influences of numerous contexts (e.g., parents, peers, community, and school) on an adolescent's risk taking behavior.

\section{Bronfenbrenner's Model of the Ecology of Human Development.}

Bronfenfrenner's theory of the ecology of human development provides the overarching conceptual framework to understand how different contexts contribute to the development of an adolescent. Bronfenbrenner (1979) asserted that human development was a product of the interaction of the individual with the environment. His model focuses on the settings within which development occurs and the interactions of the individual within and across those settings (Bronfenbrenner, 1989). The model integrates the various components that contribute to development, including the individual, the environment, and the dynamics of interactions that affect the individual within the environment (Bronfenbrenner, 1979).

Bronfenbrenner's model assumes three postulates: (a) the developing person is a dynamic entity that engages and restructures his or her environment; (b) the environment is also developing and dynamic thus mutually engaging the individual requiring a 
reciprocity of influence; and (c) the environment is not viewed as one static setting, but rather a system of interconnecting and interacting settings all relevant to the individual. Therefore, to make reference to adolescent development, it is necessary to understand each component of the systems affecting the adolescent.

Bronfenbrenner (1979) described four systems related to an individual's environment: micro-, meso-, exo-, and macrosystems. The interrelations within an individual's immediate setting are referred to as the microsystem. A micorosystem is defined as a "pattern of activities, roles, and interpersonal relations experienced by the developing person in a given setting" (p. 22). An adolescent's microsystem includes his/her family, school, and peer group. A mesosystem is an interaction of microsystems. The mesosystem is created through a linkage between two or more microsystems within which the individual directly participates, for example, processes in the family may intrude on relationships in the peer group. Exosystem refers to the environment that has an effect on an individual without being a direct part of their lives (e.g., neighborhoods). The final system is the macrosystem and it includes the "manifestation of overarching patterns of ideology and organization of the social institutions" (p. 24) that are common to the individual's culture.

Bronfenbrenner's model provides a conceptual framework for the developing adolescent. However, social learning and social control theories help to identify causes of alcohol use and other problem behaviors in the social environment. Additionally, they are the dominant theoretical perspectives in research on adolescent alcohol and other substance use (Petraitis, Flay, \& Miller, 1995). 


\section{Social Learning Theory}

Social learning theory emphasizes exposure to role models' behavior and social control theory focuses on the constraining function of social bonds. Social learning theory (Akers, 1977; Bandura, 1977) suggests that behavior is directly determined by specific environmental influences. According to this model, behaviors, such as alcohol use, are learned through the observation of others engaged in a behavior and subsequent modeling of the behavior.

Bandura modified the classic social learning theory of Akers (1977) by including other mediating constructs, such as outcome expectations and self-efficacy (Bandura 1982, 1986). Outcome expectations are the adolescent's beliefs about the likely social, personal, and physiological consequences of drug use. Bandura added to the theory then that observing role models who use drugs will not only directly affect adolescents' own drug behavior, but will also shape adolescents' outcome expectations. Bandura postulated that if an adolescent perceives that there was a positive outcome when the role model engaged in the behavior, the adolescent will be more likely to engage in the behavior himself.

Additionally, role models help shape the adolescent's self-efficacy, that is, the confidence (or lack of confidence) in one's ability to do something or to learn something new. Seeing others (especially if they are similar to oneself) perform and succeed increases the observer's confidence in trying the task. For example, when an adolescent observes his peers purchase and inhale cigarettes it provides him with the necessary knowledge and skills to obtain and use tobacco (use self-efficacy) (Flay, Hu, Siddiqui, Day, Hedeker, Petraitis, Richardson, \& Sussman, 1994). 
It is important to note that while social learning theory emphasizes social contacts with others, the direct influences of parents and peers are considered the primary social factors (Kobus, 2003). Adolescents are viewed as being most likely to imitate the behavior of those with whom they have the greatest amount of contact.

\section{Hirschi's Social Control Theory.}

Hirschi's Social Control Theory (2002) highlights the development of delinquency in an individual. His theory asserts that deviance has the opportunity to manifest when the bond between an individual and society is weakened. Hirschi gave a definition of delinquent acts which is comprised of four parts. He proposed that delinquent acts are (1) contrary to the wishes and expectations of other people; (2) they involve the risk of punishment; (3) they take time and energy; and (4) they are contrary to conventional moral belief. Given that these are the components of a delinquent act, Hirschi (2002) therefore asserts that those individuals most likely to engage in delinquent acts are (1) least likely to be concerned about the wishes and expectations of others; (2) least likely to be concerned about the risk of punishment; (3) most likely to have the time and energy to perform the act; and (4) least likely to accept conventional moral belief.

Hirschi's theory assumes that the individual performing the delinquent act is "relatively free of the intimate attachments, the aspirations, and the moral beliefs that bind most people to a life within the law" (Hirschi, 1969; p.112). Furthermore it assumes that the potential for delinquency is present in every individual and those who do not commit delinquent acts were somehow prevented from doing so. Given this, it is therefore presented that an individual's decision to refrain from the participation in delinquent behavior has been substantiated by training and is maintained by an 
individual's connection to other people (peers, family) and institutions (schools) (Hirschi, 2002).

Hirschi goes on to make a further distinction between the individual who chooses to participate in delinquent acts and the individual who does not. He proposes that the difference between a delinquent and nondelinquent is the extent to which the individual can control his or her natural motives. Control theories therefore focus on those factors that help to prevent a delinquent act from occurring as well as those factors that give an individual more opportunity for the delinquent act to manifest. For example, factors such as poverty and learning disabilities have traditionally been viewed as causes of delinquency. Within the context of social learning theory, the relationship of the factors to the act is not seen as causal. They are instead seen as factors that "weaken the conscience or reduce the effectiveness of controlling institutions" (Hirschi, 2002, p.111). Thus, poverty does not demand that an individual commit a delinquent act; instead poverty affects the likelihood that the individual will be exposed to and give in to temptation to commit the act. Given this, the individual from a "better" neighborhood, with positive peer influence will be less likely to be exposed to temptation to commit the delinquent act. Hirschi goes on to further propose several predictors of delinquency within an individual.

"Perhaps the best predictor of delinquency in American society is difficulty in school" (Hirschi, 2002, p. 114). Individuals who do poorly in school are more likely than those who do well to end up in trouble with the law. From a control perspective, this can be explained in several ways. The bonds that one creates within the school have a significant impact on the adolescent's behavior. It is therefore suggested that the student 
who is working hard to attain the grades required to pursue a career as a doctor or lawyer will not want to risk his or her investment by engaging in delinquent acts. However, the student with low grades who is not pursuing the same goals does not have the same investment. His or her behavior during his school years has little impact on what he or she will end up doing after school. He or she therefore has no stake in conforming to the rules, has formed no bonds, and is therefore more likely to engage in delinquent acts because he or she has less to lose (Hirschi, 2002).

Hirschi further connected delinquency to age. This is an important factor to include as there is a tendency for delinquency to increase rapidly in adolescence (Hirschi, 2002). Hirschi (2002) argued that this increase in delinquency appears to be a function of the increasing responsibility given to and required of the adolescent at the time. By law, for example, a 14-year-old child will not be able to go unpunished for several of the things that will go unpunished in a 7-year-old child. For example, a 7-year-old who takes something from the store will not be held to the same level of accountability as the 14year-old who takes something from a store. As the child becomes more accountable to the law, he becomes less accountable to adults in general. It is therefore asserted that delinquent behavior is most likely to occur at the point in which there is less tolerance for the individual's behavior by the law and increasingly less adult supervision - adolescence (Hirschi, 2002). Age, like difficulty in school, has a direct relationship with decreased accountability and the degree to which an adolescent is bonded to the societal institution.

The following section will further explore the individual characteristics of the adolescent and how they relate to development of, and participation in deviant behavior. 
For the purpose of this study, the following characteristics will be discussed: Age, Gender, Socioeconomic Status, Student Performance in School, and Ethnicity.

\section{Student Characteristics \& Deviant Behavior}

Research suggests that adolescent engagement in deviant behavior is linked to a number of individual characteristics. This section will be used to examine the following characteristics of age, gender, socioeconomic status, student performance in school, and ethnicity as they relate to adolescent engagement in deviant behavior.

Age

There is evidence that adolescents are more likely than children or young adults to engage in developmentally problematic behaviors (Farrington, 1986; Loeber \& Hay, 1997). Traditionally, developmental models have characterized adolescence as a period of increased risk taking (Arnett, 1999; Steinberg \& Morris, 2001). Research shows that during adolescence there are increased incidences of norm-breaking behavior, substance abuse, and risky sexual behavior (Arnett, 1992). Additionally, studies that have compared late adolescent problem drinkers with nonproblem drinkers and abstainers have found that problem drinkers exhibited more externalizing behaviors, such as truancy and delinquent behaviors (Verdurmen, Monshouwer, Van Dorsselar, TerBogt, \& Vollebergh, 2005; Best, Manning, Gossop, Gross, \& Strong, 2006). Prevalence patterns of delinquent behavior suggest that delinquent behavior is not as common in early adolescence (11-14), develops to almost universal prevalence during midadolescence (15-18), peaks during mid to late adolescent years (18-20), and decreases continuously after late adolescence (Arnett, 1999). 
Older adolescents report lower perceptions of risk than those who are younger (Gardner \& Steinberg, 2005). Some have postulated that, in adolescence, executive processes are still developing so that impulse control, foresight and other self-regulatory capacities are immature and therefore unable to modify thrill or reward-seeking behaviors (Steinberg, 2004; Gardner \& Steinberg, 2005).

\section{Gender}

Regarding gender, differences appear in patterns of participation in deviant behavior such as substance use. In fact, it has been suggested by the criminologist Sutherland (Sutherland \& Cressey, 1966) that being male is the single best demographic predictor of criminal behavior, a finding that is still argued to present day (Dornbusch, Erickson, Laird, \& Wong, 2001). It is suggested that boys involve themselves in more risk-taking behaviors than girls (Pardini, Loeber, \& Stouthamer-Loeber, 2005). In fact, males in all age groups are more likely to engage in most types of risky behavior than females (Zuckerman, 2007). Boys' beliefs about the acceptability of delinquent acts change significantly during adolescence, such that boys are more likely to endorse beliefs favoring delinquency during adolescence (Zhang, Loeber, \& Stouthamer-Loeber, 1997), and this increase in delinquent beliefs predicts subsequent escalations in antisocial and aggressive behavior (Pardini, Loeber, \& Stouthamer-Loeber, 2005). Furthermore, beliefs favoring delinquency predict subsequent increases in delinquent behavior during early and middle adolescence (Zhang, Loeber, \& Stouthamer-Loeber, 1997).

Gender was also among the strongest predictors of both late adolescent alcohol use, with males more likely to engage in this type of behavior (Duncan, Duncan, Strycker, \& Chaneton, 2002). The research has shown higher rates of alcohol and tobacco 
use among male youths aged 12-17 (SAMSHA, National Survey of alcohol and drug use, 2002-2007). Adolescent boys have higher rates of use of alcohol, frequency of use, and binge drinking than adolescent girls (Johnston, O'Malley, Bachman, \& Schulenberg, 2004). Dowdell (2006) also reported higher levels of alcohol use among boys than girls. Boys are more likely to endorse beliefs favoring delinquency during adolescence (Zhang, Loeber, \& Stouthamer-Loeber, 1997).

Historically, researchers have hypothesized that an antisocial behavior is more consistent with behavior considered appropriate for boys and inconsistent with behavior considered appropriate for girls (Heimer, 1996). Consequently, such behaviors may be reinforced by boys in the peer group (Heimer, 1996). Additionally, research suggests that mothers tolerate and sometimes encourage risky behavior to a greater extent in their sons than their daughters in playground situations both when they are teaching the child a new skill and also in free play sessions (Morrongiello \& Dawber, 2000). Although the differences in the encouragement may be a response to biological traits in boys and girls, the attitudes and behaviors of those who encourage risk behavior in boys but not girls may be internalized by children, in turn shaping future behavior (Bussey \& Bandura, 1999).

\section{Socioeconomic Status}

Low socioeconomic status puts adolescents at increased risk of engaging in risktaking behaviors (Cook, Buehler, \& Henson, 2009). In fact, results from a study involving young adolescent students show that those students from lower income families are more likely to engage in risky behavior (Rudasill, Reio, Kosine, and Taylor, 2010) 
Youth from low-income families experience higher rates of poor physical and mental health, are more likely to engage in delinquent acts, have early and unprotected sexual intercourse, and are more likely to experience adolescent pregnancy, be arrested, and drop out of school (Harris, Duncan, \& Boisjoly, 2002). Furthermore, adolescents in welfare-dependent families exhibit the worst physical and mental health, and tend to engage in earlier onset of sexual activity and greater violence (Harris, Duncan, \& Boisjoly, 2002).

Families with lower incomes often live in neighborhoods where crime rates and poverty are higher, community resources are minimal, and the children are subjected to low-quality schools (Cook, Buehler, \& Henson, 2009). Furthermore, economic stress reduces parents' abilities to be supportive and nurturing of children (McLoyd, 1990). Anderson (1999) suggested that the high prevalence rates of delinquent behavior may influence adolescents' perception that this type of behavior is normative. The perceptions, by adolescents, regarding the prevalence of engagement in delinquent behaviors are important because adolescents who overestimate the amount of substance use and cigarette smoking are more likely to engage in such behaviors (Cook, Buehler \& Henson, 2009).

\section{Student Performance in School}

Differences in an adolescents' participation in delinquent behaviors have been related to their performance in school. Individuals who perform better in school will show fewer delinquent behaviors (Bryant \& Zimmerman, 2002). Bryant and Zimmerman (2002) postulate that adolescents who do well in school and see value in schooling are less likely to increase their use of substances over time compared with 
individuals who are seemingly less concerned with their performance (Bryant \& Zimmerman, 2002). Adolescents who report that they go to school because they enjoy it and value their experiences and have expectations for continuing their education are likely to avoid choices that jeopardize their chances for success in school (Bryant \& Zimmerman, 2002).

Data suggest a strong relationship between substance use and performance at school (including attendance, grades, and graduation) (Godley, 2006). In fact, academic performance is one of the strongest and most consistent correlates of delinquency (Felson \& Staff, 2006). For example, data from the National Survey on Drug Use and Health (2004) among the general population of 12-17 year olds in the United States revealed a relationship between substance use and grades in that low grades are correlated with more frequent substance use. Hirschi (1969) suggested that the relationship between academic performance and overall delinquency is mediated by student bonding to family and school. Thus, a third variable could influence both delinquency (including substance use) and academic performance.

\section{Ethnicity}

Several studies have documented differences in the participation in deviant behavior among different groups of adolescents (Blum, Beuhring, Shew, Bearinger, Sieving, \& Resnick, 2000; Cook, Buehler, \& Henson, 2009). For example, there are numerous studies on adolescent risk behaviors that note significant differences among racial/ethnic groups (Blum et al., 2000).

A study conducted by Blum et al. (2000) examined contributions of race/ethnicity, income, and family structure to adolescent cigarette smoking, alcohol use, 
involvement with violence, suicidal thoughts or attempts, and sexual intercourse. This analysis confirms previous findings indicating higher rates of cigarette and alcohol use among Caucasian adolescents. Caucasian youths were between 1.5 and 2.5 times more likely to have smoked cigarettes in the past month than their African-American or Hispanic peers. Data from the Centers for Disease Control and Prevention (1997) also showed the same pattern of racial differences, despite the rising prevalence of cigarette smoking among adolescents in general and African-American youths in particular.

As is illustrated in the theories of the ecology of human development (Bronfenbrenner, 1979) and social control theory (Hirschi, 2002) there are a number of individual characteristics that interact with social and environmental factors to influence the development of deviant behaviors. The previous paragraphs have examined the student characteristics and how they relate to an individual's participation in deviant behavior and the following paragraphs will serve to examine the potential social and environmental influences on an individual's choice to participate in deviant behavior.

\section{Influences on Development of Deviant Behavior}

As illustrated previously, the concepts of the ecology of human development (Bronfenbrenner, 1979), social learning theory (Akers, 1977; Bandura, 1982) and social control theory (Hirschi, 2002) can be applied to better understand the development of deviant behaviors in adolescence. Ennett et al. (2008) further illustrate how these theories can be used and identify social contexts that contribute to development of the risky behaviors in adolescents.

Ennett et al. (2008) identified four social contexts (which model Bronfenbrenner's concepts of the ecology of human development) that are potentially relevant to the 
development of adolescent alcohol misuses: (1) Family; (2) Peers; (3) School (microsystem); and (4) Neighborhood (exosystem). Modeling of alcohol use by others in the adolescent's environment is measured as the central construct from social learning theory. In terms of social control theory, closeness to others, social regulation, and stress are measured as indicators of social bonds relevant to constraining deviant behaviors. Ennett et al. (2008) further described examples of how the social control variables, such as closeness to others, relate to the social contexts. For example, within the family context closeness is defined as parent-child closeness, in the peer context, feelings of closeness among mutual friends, in the school context, overall level of school bonding among all students. Voisin and Neilands (2010) illustrates how the relationships between school climate variables, such as school bonding, and risky behaviors can be partly accounted for by social control theory (Hirschi, 1969). This theory is grounded in the bonds an adolescent has to conventional society and illustrates how these conventional elements are partly represented by prosocial agents such as schools and teachers.

Weakened ties to these agents increase the probability of being recruited by, or attracted to, peers who endorse risky behaviors (Voisin \& Neilands, 2010). Furthermore, adolescents who believe that they are receiving high levels of support in school and feel that they are connected to teachers are less likely to engage in risky sexual behaviors compared with peers reporting less school support or teacher connectedness (Voisin \& Neilands, 2010). Again, control theory (Hirschi, 1969) is applicable to explaining the relationship between the school and teacher connectedness and risky sexual behaviors. For the purpose of this study the social contexts of school and peers as they contribute to development of risky behavior in adolescence will be further evaluated. 


\section{School Climate}

Schools are frequently viewed as an important context for the development of adolescent behaviors because adolescents spend much of their time in school. One aspect of the school context that can have significant impact on a student's behaviors is the perceptions and feelings regarding the school social environment. There have been a number of terms, such as school climate, school connectedness, and school bonding, used to describe these perceptions and feelings (Libbey, 2004; Maddox \& Prinz 2003). The literature states that "school climate" includes students' perceptions of interpersonal and procedural dimensions of school life. School climate is a combination of the attitudes, beliefs, values, and norms that underlie the operation of a school. School climate is motivated by how the adults in a school model and enforce these attitudes, beliefs, values, and norms. In schools with a positive school climate the adults model behaviors that engender a sense of belonging such as learning student names and calling them by their names. Adults showing a genuine concern for students and who consistently use positive reinforcement as well as respond to negative behaviors in a respectful manner also strengthen the climate (LaRusso, Romer, \& Selman, 2008).

As stated previously, a positive school climate is one in which the adults in the school model behaviors that engender a sense of belonging. A student's quality of relationship with his or her teacher therefore has the potential to contribute to a positive or negative experience for the student and influence potential outcomes (Baker, 2006; Hamre \& Pianta, 2001; and Roeser et al., 1996). Positive teacher-child relationships provide children with the positive support necessary to engage in learning activities and navigate a variety of competencies needed in the school environment (Pianta, 1999). 
Positive student-teacher relationships have been linked to children's successful adjustment to school, academic achievement, and school liking (Birch \& Ladd, 1997). On the other hand, negative student-teacher relationships in elementary school produce such outcomes as low academic achievement and low school connectedness (Birch \& Ladd, 1997).

As adolescents transition to middle school they typically report a decrease in their connectedness with teachers (Voisin \& Neiland, 2010); however, the quality of the student-teacher relationship continues to be an important factor for positive student outcomes. Specifically, the literature suggests that adolescents' positive relationships with teachers are connected to a range of healthy outcomes, such as prosocial behavior, engagement in school, and belongingness to school (Wentzel, 2002). In addition, Wentzel (2002) found teacher behaviors indicative of negative student-teacher relationships (i.e., negative feedback) are related to students' irresponsible behavior. This evidence suggests that students who are engaged positive relationships with teachers are more likely to behave prosocially and, therefore, are less likely to engage in maladaptive, risky behavior.

While research examining the link between student-teacher relationship and participation in risky behavior is limited, some studies have shown that students' perceptions of connectedness with teachers are associated with their risky behavior (Olsson et al., 2008; Voisin \& Neiland, 2010). For example in a study examining a sample of adolescent females in detention centers, Voisin et al., 2006 found low levels of connectedness with teachers are associated with reports of more risky behavior. Voisin et al. (2006), in a multiethnic sample of detained adolescent males also found that youth 
who reported low student-teacher connectedness prior to being detained were twice as likely as their peers who reported high student-teacher connectedness to engage in risky behavior. In addition, Slonim-Nevo et al. (1996), in a study of African American and White adolescents aged 11 to 18 in residential centers, reported that educational parameters such as relationships with teachers predicted AIDS knowledge, attitude (e.g., belief about condoms, drug use, and group sex), and risky sexual behaviors. Rudasill, Reio, and Stupanovic (2010) found that student-teacher conflict mediated the associations between background characteristics (i.e., gender, family income, and special services) and risky behavior. In this study, Rudasill, Reio, and Stupanovic (2010) suggests that early adolescents' relationships with significant adults (i.e., teachers) may be factors explaining why some individuals are more likely than others to engage in negative behaviors such as maladaptive risk-taking. Finally, Kassen et al. (1992) investigated causal inferences between school bonding as a marker for school engagement and risky behavior. They found that among a group of multiethnic adolescents aged 10 through 17 , school bonding was predictive of lower rates of alcohol abuse and dependency over a five-year period.

In addition to their adult models, the interactions students have within their school social environment (i.e, with their peers) play an important role in a student's socialization, norms, and aspirations for their future (Harris, Duncan, \& Bojoisly, 2002). It is suggested that certain aspects of school climate may structure norms and values; that is, when adolescents see what is common practice by other students they may assume such expectations and behaviors are socially acceptable. For example, if one of the 
school norms is to go to college, the student will expect to also go to college (Harris, Duncan, \& Bojoisly, 2002).

Gottfredson (1989) reviewed studies that examined school climate and concluded that how schools are run is directly related to the level of behavioral disruptions in schools. For example, when administration and faculty lack communication and do not work together to solve problems they have lower teacher morale and higher student disorder. Further, schools in which students do not believe they belong and feel uncared for by school faculty and staff experience higher levels of disorder (Gottfredson, 1989). On the other hand, factors such as high expectations among school staff, students, and parents for student achievement, orderly school and classroom environments, high morale among school staff and students, positive treatment of students, active engagement of students, and positive social relationships among students positively impact school climate (Stockard \& Mayberry, 1992).

Loukas and Robinson (2004) described how the influence of school climate is of particular importance during early adolescence as students' transition from one school to another. There may be a significant change in the climate of the school as they negotiate this transition. For example, young adolescents experience rapid changes in their physical, emotional, and interpersonal development; at the same time, they move from elementary to middle schools (Kuperminc, Leadbeater, Emmons, \& Blatt, 1997). This can be a difficult transition, leading to poor academic performance, self-image, perceived social support, and perception of the quality of school life (Loukas \& Robinson, 2004). Furthermore, it is suggested that some of the characteristics of the new school's environment may not be compatible with the needs of adolescents during this period of 
development making the transition more difficult. For example, needs for interpersonal affiliation and intimacy intensify during early adolescence while middle schools and their classrooms tend to be large and departmentalized. Additionally, levels of selfconsciousness and comparison of abilities are greatly enhanced at this age and middles schools tend emphasize a comparison of students' abilities (Loukas \& Robinson, 2004).

LaRusso, Romer and Selman (2008) illustrate the use of social control theory (Hirschi 1969) to help explain the positive, as well as negative, effects of school climate. The theory suggests that schools with positive school climates will help to increase students' attachment to healthy norms of behavior than schools with norms that condone risk behaviors such as drug use have more individual risk taking behavior (Kumar et al. 2002).

While there are different terms, variables, and measures used, several studies have found "school climate" to be related to health risk behaviors including smoking, drinking, drug use, truancy, and fighting (Catalano et al. 2004; Coker \& Borders 2001; Kuperminc et al. 2001; Loukas \& Robinson 2004; Roeser \& Eccles, 1998). For example, research using the data from the National Longitudinal Study of Adolescent Health showed that school connectedness was associated with lower levels of violence, tobacco, marijuana, and alcohol use (Bonny, Britto, Klosterman, Hornung, Slap, 2000; Resnick et al. 1997). International studies have shown similar results. For example, data from the World Health Organization international survey, "Health Behavior in School-aged Children," revealed that health risk behaviors were positively associated with school alienation (Larusso, Romer, Selman, 2008) and negatively associated with school satisfaction and 
positive perceptions of the school psychological environment (Samdal, Wold, Klepp, \& Kannas, 2000).

It is important to note, however, that although the discrepancy between demands and individual needs may result in emotional and behavioral difficulties, there are many early adolescents who do not develop these problems. Results may differ due to an individual's response to contextual influences. For example, perceived school climate might play a moderator role. That is, perceptions of a good quality school climate might protect adolescents from experiencing any problems (Loukas \& Robinson, 2004).

In summary, school climate is the overarching construct that pertains to the attitudes, beliefs, values and norms that underlie the operation of a school. And this perception can influence an individual in both positive and negative ways. Those individuals having a positive sense of school climate, for example, would feel that teachers would help them, school rules are fairly enforced, and teachers respect their opinions and concerns (Libbey, 2004). In other words, the student would feel respected. An important part of the construct of school climate is sense of belonging, which is used to describe a student's sense of membership or acceptance into the school and specifically involves a student's feelings about whether they are included in the school community (Ma, 2003). Sense of belonging will be discussed further in the following section.

\section{Sense of Belonging}

Sense of belonging is a construct that has been used to describe the extent to which students feel personally accepted, included, and supported in the school (Ma, 2003). A student's sense of belonging is considered to be an important part of the 
overarching construct of school climate. It has been suggested that students' lack of sense of belonging to school has consequences that may involve the participation in deviant behavior. For example, there have been studies indicating that sense of belonging can be related to gang membership, students' risk of dropping out, and academic achievement. Burnett and Walz (1994) concluded that gang-related problems increase when students do not have a sense of belonging to their school. Fine (1991) indicated that results of case studies showed that sense of belonging is a direct cause of dropping out of high school.

Others have described the positive effects of an individual's sense of belonging on one's behavior. For example, Goff and Goddard (1999) studied the relationship between core values and delinquency, substance use, and sexual behavior among high school students. Results of the analysis indicated that students who valued self-respect, sense of belonging to school, and sense of accomplishment exhibited significantly lower frequency of delinquent behavior and substance use.

A student's sense of belonging to school develops in the school social environment. Edwards (1995) examined the issues related to sense of belonging. He suggested that school administrators ensure that teachers must feel a sense of belonging to school so that they, in turn, can help their students feel a sense of belonging. In addition, Kester (1994) asserted that school structure and peer influence can interact to affect students' sense of belonging to school. For example, research consistently suggests that small high schools are in a better position than large schools to create a stronger sense of belonging (Cawelti, 1995; Ma, 2003). Attendance at small schools resulted in better student involvement, better interpersonal relationships, and easier 
management of individual and cooperative practices (Ma, 2003). In such environments where a sense of belonging is fostered, the adults show genuine concern for and familiarity with students, promoting a positive school climate (Saufler, 2005)

\section{Peer Relationships}

The interactions students have within their social environment play an important role in a student's socialization, norms, and aspirations for their futures (Harris, Duncan, \& Bojoisly, 2002). As presented by Stockard and Mayberry (1992), positive social relationships among students have the potential to influence school climate. Additionally, Kester (1994) suggested that the interaction of school structure and peer influence can interact to affect students' sense of belonging to school. It is suggested that certain aspects of school climate may structure norms and values; i.e., when adolescents see what is a common practice by other their peers they may assume such expectation and behaviors are social acceptable. For example, peer influence can be demonstrated in the form of school norms, such that, if it is a school norm to go to college, the student will also expect to go to college (Harris, Duncan, \& Bojoisly, 2002).

As adolescents gain autonomy during early adolescence and begin to focus their attention on relationships outside of the family they begin to rely more on peers as social influences who inform important choices (Ardelt \& Day, 2002; LaRusso, Romer, \& Selmer, 2008). During adolescence individuals start spending more time with friends as opposed to family (Larson \& Richards, 1991). On average, adolescents spend roughly $50 \%$ of their time with peers and $20 \%$ with parents suggesting that peers may take on increased social influence because of increased opportunities (Cook, Buehler, \& Henson, 2009). As a result, the adolescent's peers have more opportunities than parents to 
provide messages about the acceptability of deviant behavior (Pardini, Loeber, \& Stouthamer-Loeber, 2005). Given the increased opportunity, it has therefore been hypothesized that during adolescence youth will increase their reliance on peers as social influences and decrease their reliance on parents (Cook, Buehler, \& Henson, 2009).

Peer's social influence is implicated in many accounts of adolescent risk taking, because most risky behavior in which adolescents engage, such as delinquency, substance use, and reckless driving, takes place in the company of peers (Chassin et al., 2004; Simons-Morton, Lerner, \& Stinger, 2005). An illustration of this increased reliance on peers is found in the criminology literature. There is some evidence to suggest that when some adolescents participate in deviant acts, such as drug/alcohol use, they do so with their peers (Zimring, 1998; Gardner \& Steinberg, 2005). As opposed to adults who typically do so alone, adolescents engage in deviant acts accompanied by one or more peers (Gardner \& Steinberg, 2005). In addition, the research suggests that the average adolescent is more likely than not to report having friends who use drugs (Marshal \& Chassin, 2000). For example, a national school survey indicated that $76 \%$ of $8^{\text {th }}$ graders and $92 \%$ of $10^{\text {th }}$ graders reported having friends who use alcohol (Marshal \& Chassin, 2000). Given these numbers it is important to further examine the influence of peers in adolescent substance use and risk-taking behaviors.

Peer influence theorists suggest that an adolescent's selection of peers has a strong impact on the likelihood to engage in problem drinking (Ennett, et al., 2008). Association with drug using peers has been suggested to be one of the strongest single predictors of substance use among youth and adolescents (Coker \& Borders, 2001). In example, studies have shown that adolescents with alcohol-using peers are more likely to 
use alcohol than adolescents without drinking friends (Bahr, Hawks, and Wang, 1993; Donovan and Jessor, 1983; Fisher and Bauman, 1988). The collective nature of risktaking behavior among adolescents is more generally illustrated by Gardner and Steinberg (2005). Their findings indicate that exposure to peers during a risk-taking task, in which the adolescent plays a computer game and is required to make actual decisions in a risky driving situation, doubled the amount of risky behavior among middle adolescents, increased it by $50 \%$ among college undergraduates, and had no impact at all among adults, reiterating the increased influence of peers on adolescent's behavior.

Investigations by Hawkins, Catalano and Miller (1992) have demonstrated similar results that alcohol use by adolescents' friends, for example, is substantially associated with adolescents' alcohol use. Predictably, friends' cigarette smoking is related to adolescents' smoking, and friends' use of hard drugs is related to adolescents' drug use (Lynskey, Fergusson, \& Horwood, 1998). Such findings lend credence to Prinstein, Boergers, and Spirito's (2001) broad conclusion that affiliation with risk taking peers is related to increases in adolescents' risk behavior over time.

Peer influence has also been suggested in adolescent's risky driving behavior. Adolescent drivers tend to engage in numerous risky behaviors including speeding which has been found to significantly correlate with a greater risk for accidents (Elander, West, \& French, 1993). Adolescents are more likely than adults to drive recklessly and to drive while intoxicated (Gardner \& Steinberg, 2005). They are more likely to exhibit and report greater risk-taking such as following too closely, unsafe accelerations, and rapid lane changes (Jonah, 1986; 1990; Preusser, Ferguson, \& Williams, 1988). Lack of driving experience has been viewed as a major contributing factor in adolescent driving 
problems. However, Gregersen and Bjurulf (1996) examined a model in which other factors were shown to influence driver behavior, such as attitudes of others. Teenagers who socialize with others who display risky behaviors are more likely to engage in that type of behavior (Gerra et al., 1999; Jessor, Turbin, \& Costa, 1997; West \& Hall, 1997).

In the same line of research, it has been postulated that adolescents who affiliate with delinquent peers are at risk for several negative outcomes (Pardini, Loeber, \& Stouthamer-Loeber, 2005). For example, increased levels of affiliation with peers engaging in deviant behavior are associated with increased aggression (Capaldi, Dishion, Stoolmiller, \& Yoerger, 2001), self-reported delinquency (Vitaro, Brendgen, \& Tremblay, 2000), arrests (Patterson, Dishion, \& Yoerger, 2000), and the initiation of substance use (Dishion, Capaldi, Spracklen, \& Li, 1995). It has been hypothesized that one of the mechanisms behind the peer influence is the impact of favorable beliefs about delinquency (Pardini, Loeber, \& Stouthamer-Loeber, 2005).

Clearly, the norms and values established by peers can have negative and/or positive impact on school climate by affecting student perceptions, beliefs, and expectations concerning themselves, their behavior, and their futures.

\section{Protective Factors}

In order to predict the initiation and maintenance of risky behaviors, it is important also to examine those factors which buffer or decrease risk of deviant behavior. These positive influences have been defined as protective factors, or "those factors that reduce the likelihood of problem behavior," by mediating the effect of the exposure to participation in deviant behaviors (Arthur, Hawkins, Pollard, Catalano, \& Baglioni, 2002, p.576). Protective Factors have also been identified as individual or environmental 
factors (such as student characteristics and schools) that reduce the effects of stressful life events; increase an individual's ability to avoid risks; and promote social and emotional competence to thrive in all aspects of life (Kipke, 1999). These protective factors are now being measured by federal, state, and community prevention planners in their prevention needs assessments to more adequately evaluate the variables mediating adolescent deviant behavior.

Losel (1994) examined the positive/protective effect of social resources on adolescents who were deemed at high risk for engaging in antisocial (deviant) behavior. This research found significant predictors of not engaging in antisocial behaviors to include: "the presence of an emotional reference person, a satisfying social support network, and an institutional climate characterized by openness, autonomy, cohesion, organization, and a low level of conflict" (Losel, 1994, p. 292).

In addition, Beam et al. (2002) demonstrated that adolescents who have warm, supportive people in their lives have better outcomes. In other words, these adolescents have protective factors safeguarding them from engaging in deviant behaviors (Burton \& Marshall, 2005). Based on these studies by Beam et al. (2002), they suggest that nonparental very important people could provide a protective effect where they serve as positive role models who are supportive of the adolescent. This is important as not all adolescents have a positive adult in their life and these studies suggest a great need for adolescents to form bonds with positive role models (Burton \& Marshall, 2005).

A study conducted throughout Britain investigated many risk and protective factors for youth (Beinart, Anderson, Lee, \& Utting, 2002). The authors concluded that 
social bonding was an important protective factor for a large proportion of youth; those youth who were able to relate well to adults outside their family (such as teachers) were at reduced risk of engaging in deviant behavior. Overall conclusions of this study indicated that youth needed to feel involved in their communities, families and schools and they required recognition and praise for their efforts (Beinart et al., 2002). Burton and Marshall (2005) further suggest that such involvement could lead to lower participation in delinquent acts, as the individual may not want to harm the relationships they have formed and they may feel distress about harming the community to which they have bonded.

Relationships with prosocial peers (i.e., peers who have positive social and psychological capabilities and responsibilities) may also act as a buffer against risky behavior (Coker \& Borders, 2001). For example, Catalano, Kosterman, Hawkins, Newcomb, and Abott (1996) found relationships between the prosocial opportunities, prosocial involvement, prosocial bonding and an absence of antisocial behavior including substance use.

The perception of a positive school climate may help to mediate the use of substances (Weishew \& Peng, 1993). A positive school climate consists of teacheradministrator cooperation, positive teacher attitudes toward students, sense of community, teacher praise, and attitudes emphasizing the expectation of academic success (Weishew \& Peng, 1993). Weishew and Peng (1993) found that schools with better climates, more positive student perceptions, and fair discipline were associated with lower rates of misbehavior among eighth graders. Additionally, using the Social Ecology Model of adolescent substance use, Kumpfer and Turner (1991) suggested that 
youth who bond to prosocial institutions (e.g., schools) are less vulnerable to the effects of negative peers and subsequent substance use. They suggest that the bonding to school is dependent on perceptions of positive school climates (Coker \& Borders, 2001).

Sense of belonging to school, as a key component of positive school climate, can be a buffer or protective factor against negative outcomes such as risk behavior. Blum and Rinehart (1996) found that students who felt more connected to their school showed lower at-risk behaviors and attitudes than did students who did not report feeling connected. Additionally, Anderman (2002) found that higher levels of belonging were associated with higher levels of optimism and lower levels of depression, social rejection and school problems. The National Longitudinal Study of Adolescent Health looked at the impact of protective factors on adolescent health and well being among more than 36,0007 th $-12^{\text {th }}$ grade students. The study suggested that students are more likely to engage in healthy behaviors and succeed academically when they feel connected to school. The study found that family, school, and individual factors such as school connectedness, parent family connectedness, high parental expectations for academic achievement, and the adolescent's level of involvement in religious activities and perceived importance of religion and prayer were protective against a range of risky behaviors (Resnick, Harris, \& Blum, 1993). School connectedness was found to be the strongest protective factor for both boys and girls to decrease substance use and risk of unintentional injury (e.g.,drinking and driving, not wearing seatbelts) (Resnick, Bearman, \& Blum, 1997). Research has also demonstrated a strong relationship between school connectedness and educational outcomes, including school attendance; staying in school longer; and higher grades and classroom test scores (McNeely, 2003). 
To further bolster the connection between sense of belonging and decreased levels of at-risk behavior, an adolescent's attachment to school, as a part of school bonding, has also been identified as a variable that may help to prevent and/or delay adolescent use of alcohol (Henry \& Slater, 2002). An individual's school attachment has been consistently identified as a protective factor. A strong attachment to school is characterized by a commitment to conventional academic and social endeavors at school, attachment to prosocial peers, attachment to teachers and other school staff, and belief in established prosocial norms.

Similarly, Hirschi's Control Theory highlights the importance of bonding to the institution of the school. This theory posits that bonding within a school consists of four elements: 1) involvement in the school, 2) emotional attachment with others, 3) investment or commitment to the school, and 4) belief in the values of the school. This type of bonding, once strongly established, is the mechanism by which deviant behavior, in particular, is inhibited (Catalano, Haggerty, Oesterle, Fleming, \& Hawkins, 2004).

There is much empirical support for the inhibitory effect of school bonding on deviant behavior (Hirschi, 1969; Resnik et al., 1997; Werner \& Smith, 1992). In a longitudinal study, strong school bonding was associated with less tobacco, alcohol, and drug use, and other delinquent behaviors (Catalano et al., 2004). This study illustrates the inverse of Hirschi's assumption, that without strong school bonds, students are not constrained to resist at-risk behaviors.

\section{Engagement in deviant behavior and its effects}

The societal costs of youth engagement in deviant behaviors, such as substance use and risky driving, are exceptionally high (Kaufmann, Wyman, Forbes-Jones, \& 
Barry, 2007). In the United States, the consequences of underage drinking cost an estimated $\$ 53$ billion in 1998 (Zakrajsek \& Shope, 2006). The consequences include injury, violent crime and treatment for alcohol abuse. In fact, injury, primarily from motor-vehicle crashes, continues to be the leading cause of death among adolescents and young adults in the United States (Zakrajsek \& Shope, 2006), and adolescents continue to have one of the highest motor-vehicle crash rates of all age groups (National Highway Traffic Safety Association [NHTSA], 2006). In 2004, 30\% of 16-20 year-old drivers killed in motor-vehicle crashes had been drinking (NHTSA, 2006). Furthermore, a relationship between risky driving, defined as deliberately taking risks while driving, and other problem behaviors, such as alcohol consumption, has been found in adolescence (Jessor, 1987, Zakrajsek \& Shope, 2006).

Despite a nationwide legal drinking age of 21 , many individuals in the United States begin drinking in adolescence (Zakrajesek \& Shope, 2006). Nationally, alcohol use rates begin to rise in adolescence, peak around age 21, and remain high well into adulthood (Substance Abuse and Mental Health Services Administration [SAMHSA], 2003). Results from the 2005 Monitoring the Future study found $41 \%$ of 8 th grade students had consumed an alcoholic drink ("not just a few sips"), and 20\% had been drunk (Johnston, O'Malley, Bachman, \& Schulenberg, 2004).

The participation in deviant behaviors as an adolescent can have lasting impacts into adulthood. Adult health outcomes have been linked to the behaviors in which they engaged as children and adolescents. In fact, any health risk behaviors that are established during adolescence can be difficult to change in adulthood (Dowdell, 2006). 
These behaviors include the use of alcohol and tobacco and can place an adolescent at high risk for continuing unhealthy lifestyles (Dowdell, 2006).

The abuse of alcohol and illicit drugs is associated with serious health problems in the United States, including violence, injury, HIV infection, and AIDS (Dowdell, 2006). Among individuals ages 15-34, higher alcohol consumption patterns predict motor vehicle, work, and sports accidents (Dowdell, 2006). Additionally, reports of the annual economic costs from alcohol abuse were estimated to be 185 billion in 1998 (National Institute on Alcohol and Alcoholism, 2000).

In regards to the effects of tobacco use, the statistics report that tobacco-related deaths number more than 430,000 per year among U.S. adults (USDHHS, 2000). It is also estimated that direct medical costs attributable to smoking total at least $\$ 50$ billion a year (USDHHS, 2000). Despite these alarming statistics, reports show that each day more than 3,000 adolescents across the United States become daily smokers (CDC, 2001). Twenty-five percent of high school students have reported smoking a whole cigarette before the age of 13 (USDHHS, 2000). Additionally, 3 out of 4 teenage smokers have tried to quit smoking at least once but failed (Ferguson \& Ferguson, 2000; Fritz, 2000).

There is a tremendous cost of adolescent participation in deviant behavior. It has immediate and long-lasting impacts not only on the individual engaging in the act but on society as a whole. Clearly, a thorough understanding of what contributes to and influences the development of deviant behavior is important. 


\section{Research Questions}

Given the complex relationships between age, gender, socioeconomic status, school performance, and ethnicity to school climate and their influences on deviant behavior, this study proposes the research questions below. The first question will address data gathered at the student-level and the second question will address student data aggregated to the school level.

Question 1. In a large, urban school system, to what extent do student-level gender, ethnicity, and age contribute to the prediction of students' self reports of risky behavior?

Hypothesis 1: Gender, ethnicity, and age will be significant predictors of student participation in risky behaviors such that males, Caucasians, and older adolescents will show more frequent participation in risky behaviors.

Question 2. In a large, urban school system, to what extent do student data, aggregated to the school-level, of age (middle or high school), free/reduced lunch status, school performance on standardized testing, and perception of school climate contribute to the prediction of students' self reports of risky behavior?

Hypothesis 2: Student data aggregated to the school level of school level status (middle vs. high school), free/reduced lunch status, school performance on standardized testing, and school-level perception of school climate will be significant predictors of students' self report of risky behaviors aggregated to the school level such that high schools, schools with majority free/reduced lunch status, schools with lower scores on 
standardized testing, and schools with less positive perceptions of school climate will show more frequent participation in risky behaviors. 


\section{CHAPTER III}

\section{METHODS}

In this chapter, the research methods of these survey-based, school-level analyses will be presented in the following sections: sample, materials, procedure, and data analysis.

\section{Sample}

This study is based on data gathered from 15,299 Middle School students and 16,390 High School Students who completed surveys administered by a large, Midwestern, urban school district during the 2007-2008 school year. The purpose of using this sample of middle and high school students was to be able to generalize these results to the adolescent population, ages 11-20. Additional data were used from the Safe and Drug Free Schools Survey administered in conjunction with the Comprehensive School Survey. The Safe and Drug Free Schools Surveys were completed by staff, parents, and students in grades 4-12. Data from the Safe and Drug Free Schools Survey $(\mathrm{N}=15,299$ Middle School students, response rate $=77 \% ; \mathrm{N}=16,390$ High School students, response rate $=62 \%$ ) were used to address the substance use and risky driving behavior of adolescents. For the purpose of this study, Middle and High School student data was analyzed to represent the adolescent population.

Demographics describing the sample of participating Middle and High School students from the school year 2007-2008 are presented in Tables 1 and 2 . 
Table 1

Middle School Participants' Socio-Demographic Information, 2007-2008 school year

\begin{tabular}{|c|c|c|}
\hline \multirow[t]{2}{*}{ Variable } & \multicolumn{2}{|c|}{$\begin{array}{c}\text { Whole Sample } \\
(\mathrm{N}=15,299)\end{array}$} \\
\hline & $\mathrm{N}$ & Percentage \\
\hline Student Gender & 14,710 & \\
\hline Male & 7,282 & 49.50 \\
\hline Female & 7,428 & 50.50 \\
\hline Student's Ethnicity & 14,673 & \\
\hline African American & 4,824 & 32.88 \\
\hline White & 7,941 & 54.41 \\
\hline Latino & 543 & 3.70 \\
\hline Other & 1,365 & 9.30 \\
\hline Free/Reduced Lunch Status & 13,686 & \\
\hline Yes & 7,470 & 54.58 \\
\hline No & 6,216 & 45.42 \\
\hline Age & 14,797 & \\
\hline 10 & 10 & 67.58 \\
\hline 11 & 2,327 & 15.73 \\
\hline 12 & 4,591 & 31.03 \\
\hline 13 & 4,841 & 32.72 \\
\hline 14 & 2,712 & 18.33 \\
\hline $15+$ & 316 & 2.13 \\
\hline
\end{tabular}


Table 2

High School Participants' Socio-Demographic Information, 2007-2008 school year

\begin{tabular}{|c|c|c|}
\hline \multirow[t]{2}{*}{ Variable } & \multicolumn{2}{|c|}{$\begin{array}{c}\text { Whole Sample } \\
(\mathrm{N}=16,390)\end{array}$} \\
\hline & $\mathbf{N}$ & Percentage \\
\hline Student Gender & 15,529 & \\
\hline Male & 8,114 & 52.25 \\
\hline Female & 7,415 & 47.75 \\
\hline Student's Ethnicity & 15,489 & \\
\hline African American & 4,878 & 31.49 \\
\hline White & 8,636 & 55.76 \\
\hline Latino & 674 & 4.35 \\
\hline Other & 1,301 & 8.40 \\
\hline Free/Reduced Lunch Status & 14,591 & \\
\hline Yes & 6,483 & 44.43 \\
\hline No & 8,108 & 55.57 \\
\hline Age & 15,650 & \\
\hline 13 & 31 & .20 \\
\hline 14 & 1,915 & 12.24 \\
\hline 15 & 4,020 & 25.69 \\
\hline 16 & 4,059 & 25.94 \\
\hline 17 & 3,574 & 22.84 \\
\hline 18 & 1,741 & 11.12 \\
\hline $19+$ & 310 & 2.00 \\
\hline
\end{tabular}


For the purpose of this study, the data was also examined at the school level.

Therefore the second sample used the student data aggregated to the school level to represent each school. School level data is presented in Table 3.

Table 3

School level data for the 2007-2008 school year

\begin{tabular}{|c|c|c|c|c|c|c|}
\hline Variable & $\mathrm{N}$ & Mean & $\begin{array}{l}\text { Standard } \\
\text { Deviation }\end{array}$ & Range & Minimum & Maximum \\
\hline $\begin{array}{l}\text { School Level Status } \\
\text { (Middle vs High } \\
\text { School) }\end{array}$ & 42 & 1.50 & 0.51 & 1.00 & 1.00 & 2.00 \\
\hline School Climate & 42 & 32.54 & 2.27 & 10.01 & 27.63 & 37.63 \\
\hline Test Scores & 42 & 75.65 & 16.23 & 65.40 & 44.30 & 109.70 \\
\hline $\begin{array}{l}\text { Free/Reduced Lunch } \\
\text { Status (percent) }\end{array}$ & 42 & 55.57 & 20.70 & 79.10 & 12.20 & 91.30 \\
\hline Risky Behavior & 42 & 36.57 & 2.23 & 7.26 & 32.24 & 39.50 \\
\hline
\end{tabular}




\section{Measures}

Two instruments were used in this research. They include the Comprehensive School Survey (CSS) and the Safe and Drug Free Schools Survey.

\section{The Comprehensive School Survey (CSS)}

The CSS is provided to all staff, all parents, and students in grades 4-12 for the purpose of collecting data concerning academic indicators, school community, empathy, ethics, service, environment, safety, and employee job satisfaction. The CSS measures the opinions of students, parents, staff, and teachers in JCPS using Likert-type scale items (i.e., 1 = Strongly Agree, $2=$ Agree, $3=$ Disagree, and $4=$ Strongly disagree) as well as Yes/No questions.

There are six versions of the CSS as it is adapted to the populations of interest: elementary students, middle school students, high school students, parents, classified staff, and certified staff. Each survey is divided into sections. The three student surveys (elementary, middle, and high) are organized into the following sections: (A) Student Characteristics, (B) School, (C) Home/Community, (D) Personal Development, and (E) School Operation. Surveys measure student, parent, and staff perceptions of a range of issues related to academic rigor and school climate. Components of school climate measured by the survey include: belonging, sense of community, connectedness, teacher support, and student -student and student-teacher relationships. Both school-based and non-school based certified and classified surveys are divided as follows: (A) Background

Characteristics, (B) Students, (C) School Operation, and (D) Employee. The Parent Survey layout is similar - (A) Background Characteristics, (B) Students, (C) School Operation, and (D) Parent/Guardian. 
Analyses have been conducted on the instruments to ensure that they possess reasonable levels of validity and reliability in these contexts. Muñoz (2008) conducted a reliability study for: each survey as a whole; each domain within each survey; and for each construct within each domain. Item-by-item correlations with Cronbach's alphas were conducted using the Statistical Package for the Social Sciences (SPSS). Findings showed that the coefficient alphas greatly exceeded the minimum (.60) recommended for use of composite scales in statistical analyses (Nunally \& Bernstein, 1994).

Responses to the surveys for the 2007-2008 school year were analyzed with exploratory component analysis, an analytical approach that allows for the exploration of trends in individuals' responses to items on the surveys. Initial analyses were performed to see if different components emerged and to see if they fit together to measure a broader concept. Data were analyzed using exploratory component analysis. Examinations of the responses to surveys revealed some common trends across all groups (Rudasill \& Rakes, 2008). Analyses with subgroups of responses on the middle school and high school student survey supported seven and eight components respectively. For the purpose of this study, the construct of School Support was used to assess perception of school climate.

School Support Survey (Middle School and High School). The Middle School scale consists of 11 items and taps into engagement, student belonging, and school climate. The High School scale consists of 12 items and taps into similar items. These items were assessed by answering Strongly Agree, Agree, Disagree, or Strongly Disagree. Specific items are presented in Table 4 and 5. 
Table 4

Middle Schools, School Support Items

\begin{tabular}{|l|l|}
\hline B01 & I learn interesting and useful things at school \\
\hline B02 & I think school is fun and challenging. \\
\hline B03 & I enjoy going to school. \\
\hline B06 $\quad$ I feel like I am part of my school community.
\end{tabular}

B08 My teachers respect my opinion in class even if it disagrees with their opinions.

B11 I feel my teachers really care about me.

B12 I believe I can talk with my counselor dean

B13 My school provides a caring and supportive environment for students.

B17 I am very satisfied with my school.

B18 I would rather go to this school than any other school.

B19 I am very satisfied with JCPS.

Table 5

High School, School Support Items

\begin{tabular}{|l|l|}
\hline B01 & I learn interesting and useful things at school \\
\hline B02 & I think school is fun and challenging. \\
\hline B03 & I enjoy going to school. \\
\hline B06 & I feel like I am part of my school community.
\end{tabular}

B11 I feel my teachers really care about me.

B19 I believe I will be prepared to go to the next grade level in school.

B20 My JCPS education will prepare me for employment.

B21 My school does a good job of preparing me for college.

B22 I believe I am developing essential skills for life (such as reading, writing, and math) in JCPS.

B23 I am very satisfied with my school. 
B24 I would rather go to this school than any other school.

B25 I am very satisfied with JCPS.

\section{The Safe and Drug Free Schools Survey}

The Safe and Drug Free Schools Survey is administered in conjunction with the CSS. This survey addresses substance use, safety concerns (i.e., feeling unsafe at school, outside the building, or on the way to or from school) and driving behavior. For the purpose of this study, items addressing risky behavior (i.e., substance use behavior) will be analyzed. Additionally, surveys indicate the students' gender, ethnicity, grade in school, age, and free/reduced lunch status.

Risky Behavior. These items evaluate the frequency of students' use of substances, such as alcohol, marijuana, other illegal drugs, and cigarettes. Students are asked to respond to items using a Likert scale indicating the frequency of use of the substance: 0 times; $1-3$ times; $4-5$ times; 7 or more times. Specific items are presented in Table 6. The reliability of this scale was examined using Cronbach's coefficient alpha. The Risky Behavior scale was found to demonstrate a high level of consistency $(\alpha=$ $.918)$. 
Table 6

Risky Behavior Questions

1. How many occasions (if any) have you had alcohol to drink in your lifetime? (beer, wine or hard liquor-more than just a few sips)

2. How many occasions (if any) have you had alcohol to drink in the past 30 days? (beer, wine or hard liquor-more than just a few sips)

3. How many occasions (if any) have you had five or more drinks of alcohol in a row in your lifetime?

4. How many occasions (if any) have you had five or more drinks of alcohol in a row in the past 30 days?

5. How many occasions (if any) have you smoked marijuana (weed, pot) in your lifetime?

6. How many occasions (if any) have you smoked marijuana (weed, pot) in the past 30 days?

7. How many occasions (if any) have you used other illegal drugs in you lifetime?

8. How many occasions (if any) have you smoked cigarettes or used other tobacco products in your lifetime?

9. How many occasions (if any) have you smoked cigarettes or used other tobacco products in you lifetime?

10. How many occasions (if any) have you smoked cigarettes or used other tobacco products in the past 30 days?

\section{Procedure}

Data for this study were gathered in 2008 and for the purpose of this study only middle and high school data was examined. All student surveys were made available on CASCADE. Student survey response bubble sheets were printed from the CASCADE system and administered to students by their teachers. Parent and staff surveys were made available on the JCPS online System on the district's website. Additionally, paperand-pencil surveys were provided for parents without computer access. Parent and staff surveys were made available on JCPS during the same week and a special PONY was made available to pick up all parent paper-and-pencil surveys from schools

Results of the surveys were tabulated and a report produced for each discrete group of respondents by location, level and district-wide and made available to each respective location 8-12 weeks later. The surveys were self-administered and provided through email, posting on the World Wide Web, and optical imaging of paper surveys. This allowed for the distribution of large quantities of surveys in order to increase the 
response rate, to be processed quickly but with great accuracy, and to potentially look at individual student results. A total of 15,299 Middle School students completed the questionnaire with a response rate of $77 \%$. A total of 16,390 High School students completed the questionnaire with a response rate of $62 \%$. 


\section{CHAPTER IV}

\section{RESULTS}

Two primary research questions were addressed. The results of these analyses are presented in the same sequence as described in the methods chapter under data analysis procedures.

\section{Student Level Analysis}

\section{Risky behavior as it relates to student level gender, ethnicity, and age.}

Hypothesis 1 states that gender, ethnicity, and age will be significant predictors of student participation in risky behaviors such that males, Caucasians, and older adolescents will show more frequent participation in risky behaviors.

As can be seen in Table 8, using a multiple regression analysis, risky behavior was regressed on student-level gender $($ male $=1$; female $=2$ ), ethnicity (white $=1$; nonwhite $=2$ ), and age. The hypothesis that gender, ethnicity, and age were significant predictors for participation in risky behaviors was significant at $\left(\mathrm{F}_{3,27,662}=1774.197, \mathrm{p}<\right.$ $\left..001, R^{2}=.161\right)$. The $\mathrm{R}^{2}$ indicates $16.1 \%$ of the variance in participation in risky behaviors was accounted for by gender, ethnicity, and age. All three predictors were significant such that males $(M=36.21 ; \mathrm{SD}=6.53)$ endorsed more frequent participation in risky behaviors than females $\left(\mathrm{M}=36.41, \mathrm{SD}=6.01, f^{2}=0.19\right)$; whites $(\mathrm{M}=35.69$; $\mathrm{SD}=6.84$ ) endorsed more frequent participation in risky behaviors than racial and ethnic minorities (non-whites $\mathrm{M}=37.05 \mathrm{SD}=5.48, f^{2}=0.19$ ) and older students endorsed more frequent participation in risky behaviors than younger students. For example, 19 year- 
olds $(\mathrm{M}=28.96, \mathrm{SD}=11.03)$ endorsed the most participation in risky behavior and 11 year-olds endorsing the least frequent participation in risky behavior $(\mathrm{M}=39.46, \mathrm{SD}=$ $1.83, f^{2}=0.19$ ). It is important to note that higher scores indicate less participation in deviant behavior; i.e., a maximum score of 40 indicates no participation in risky behaviors.

Table 7

Linear Regression Predicting Risky Behaviors from Age, Gender, and Ethnicity $(N=27,666)$

\begin{tabular}{|c|c|c|c|c|}
\hline Variable & $B$ & $S E B$ & $\beta$ & $t$ \\
\hline Age & -1.17 & .02 & $-.39^{* * *}$ & -70.15 \\
\hline Gender & .20 & .07 & $.02^{* *}$ & 2.90 \\
\hline Ethnicity & 1.32 & .07 & $.11^{* * *}$ & 19.14 \\
\hline
\end{tabular}

${ }^{*} p<.05,{ }^{* *} p<.01, * * * p<.001$

All three predictors were shown to be correlated with participation in risky behaviors. However, as presented in Table 8 the three predictors of age, gender, and ethnicity were not highly correlated with each other. The following table shows the correlation of each predictor with participation in risky behaviors as well as with each other. 
Table 8

Correlations Among Student Level Data: Age, Gender, Ethnicity, and Risk Behaviors

$(N=27.666)$

\begin{tabular}{|l|l|c|c|c|}
\hline Variable & 1. & 2. & 3. & 4. \\
\hline 1. Age & - & .002 & $-.010^{*}$ & $-.387^{* * *}$ \\
\hline 2. Gender & & - & $.010^{*}$ & $.016^{* *}$ \\
\hline 3. Ethnicity & & & - & $.109^{* * *}$ \\
\hline 4. Risk Behaviors & & & & - \\
\hline
\end{tabular}

${ }^{*} p<.05,{ }^{* *} p<.01,{ }^{* * *} p<.001$

\section{School Level Analyses}

\section{Risky behavior as it relates to student data aggregated to the school level.}

Hypothesis 2 states that student data aggregated to the school level (middle or high school), school-level perception of school climate, school performance on standardized testing, and free/reduced lunch status will be significant predictors of students' self report of risky behaviors aggregated to the school level such that high schools, schools with majority free/reduced lunch status, schools with lower scores on standardized testing, and schools with less positive perceptions of school climate will show more frequent participation in risky behaviors.

Using a Multiple Regression analysis, data from the scale measuring school level risky behavior was regressed on student data aggregated to the school level on School Level Status (middle or high school), perception of school climate, school performance on standardized testing, and free-reduced lunch status. As can be seen in Table 9, the regression equation resulted in a significant linear relationship $\left(\mathrm{F}_{3,42}=48.82, \mathrm{p}<.001, R^{2}\right.$ 
$=.841)$. The $R^{2}$ indicated that $84.1 \%$ of the variance in school-level participation in risky behaviors was accounted for by school level status (middle vs high school). School level status (middle or high) was the only variable that predicted the participation in risky behaviors such that high schools $(\mathrm{M}=34.39 ; \mathrm{SD}=2.53)$ were more likely to participate in risky behaviors than middle schools $\left(\mathrm{M}=38.18 ; \mathrm{SD}=1.53, f^{2}=5.29\right)$. Again, higher scores indicate less frequent participation in risky behaviors.

Table 9

Linear Regression Predicting Risk Behaviors from School Level Status, School Climate, Performance on Standardized Testing and Free-Reduced Lunch Status $(N=42)$

\begin{tabular}{|l|c|c|c|c|}
\hline & $B$ & SEB & $\beta$ & $t$ \\
\hline School Climate & .14 & .14 & .15 & 1.00 \\
\hline School Level Status & -4.21 & .67 & $-.96^{* * *}$ & -6.28 \\
\hline Test Scores & .03 & .03 & .22 & .926 \\
\hline FreeReduced Status & .01 & .02 & .09 & .429 \\
\hline
\end{tabular}

$* \mathrm{p}<.05 ; * * \mathrm{p}<.01 ; * * * \mathrm{p}<.001$

Table 10

Correlations Among School Level Data and Risk Behaviors (N=42)

\begin{tabular}{|l|c|c|c|c|c|}
\hline Variable & 1 & 2 & 3 & 4 & 5 \\
\hline 1. School Climate & -- & $.69^{* * *}$ & $.49^{* * *}$ & $-.56^{* * *}$ & $-.45^{* *}$ \\
\hline $\begin{array}{l}\text { 2. School Level } \\
\text { Status }\end{array}$ & & -- & $-.06^{*}$ & -.20 & $.89^{* * *}$ \\
\hline 3. Test Scores & & & -- & $-.90^{* * *}$ & $.28^{*}$ \\
\hline $\begin{array}{l}\text { 4. Free Reduced } \\
\text { Status }\end{array}$ & & & & -- & .001 \\
\hline 5. Risk Behavior & & & & & -- \\
\hline
\end{tabular}

${ }^{*} \mathrm{p}<.05 ; * * \mathrm{p}<.01 ; * * \mathrm{p}<.001$ 
Because high correlations between the school-level variables of free/reduced lunch status and standardized test scores $(\mathrm{r}=-.90)$ created multicollinearity issues (as seen in Table 10), a second set of analyses was conducted in which standardized test scores were removed from the equation. In this second Multiple Regression analysis schoolrisky behavior regressed on student data aggregated to the school level of school level status (middle or high school), perception of school climate, and free-reduced lunch status. As can be seen in Table 11 below, the regression equation resulted in a significant linear relationship $\left(\mathrm{F}_{3,38}=64.02, \mathrm{p}<.01, R^{2}=.835\right)$. The $R^{2}$ indicates $83.5 \%$ of the variance in participation in risky behaviors was accounted for by school level status (middle vs high school) and school climate. School level status and School climate were significant predictors of participation in risky behaviors. Age predicted participation in risky behaviors such that high school students $(\mathrm{M}=34.39 ; \mathrm{SD}=2.53)$ were more likely to participate in risky behaviors than middle school students $\left(\mathrm{M}=38.18 ; \mathrm{SD}=1.53, f^{2}=\right.$ 5.06). School Climate predicted participation in risky behavior such that those individuals with more positive school climate scores endorsed less frequent participation in risky behaviors. Table 12 below shows the correlation between variables.

Table 11

Linear Regression Predicting Risk Behaviors from Age, School Climate, and FreeReduced Lunch Status $(N=42)$

\begin{tabular}{|l|l|l|l|l|}
\hline & $B$ & $S E B$ & $\beta$ & $t$ \\
\hline School Climate & .27 & .10 & $.27^{*}$ & 2.72 \\
\hline $\begin{array}{l}\text { School Level } \\
\text { Status }\end{array}$ & -4.76 & .41 & $-1.08^{* *}$ & -11.65 \\
\hline $\begin{array}{l}\text { Free/reduced } \\
\text { Lunch Status }\end{array}$ & -.24 & .34 & -.05 & -.72 \\
\hline
\end{tabular}


Table 12

Correlations Among School Level Data and Risk Behaviors $(N=42)$

\begin{tabular}{|l|c|c|c|c|}
\hline Variable & 1 & 2 & 3 & 4 \\
\hline 1. School Climate & -- & $.69^{* * *}$ & $-.41^{* *}$ & $-.45^{* *}$ \\
\hline 2. School Level Status & & -- & -.15 & $-.89^{* * *}$ \\
\hline 3. Free Reduced Status & & & -- & -.002 \\
\hline 4. Risk Behavior & & & & -- \\
\hline
\end{tabular}

$$
\mathrm{p}<.05 ; *^{* *} \mathrm{p}<.01 ; * * * \mathrm{p}<.001
$$




\section{CHAPTER V}

\section{DISCUSSION}

This study was conducted to examine the extent to which the student characteristics of age/school level, gender, socioeconomic status, student performance in school, and ethnicity, as well as student perceptions of school climate contribute to the participation in risky behaviors. This goal was accomplished by examining data at the student level and the school level of middle and high school student self reports of risky behaviors. Student level data included the examination of student self reports of risky behaviors as they relate to age, gender, and ethnicity. Student level data aggregated to the school level included student level status (middle vs high school), free/reduced lunch status, school level self-report of school climate, and school level performance on standardized test scores. This study provides support to existing literature (Cook, Buehler, \& Henson, 2009; Zhang, Loeber, \& Stouthamer-Loever, 2005; Gardner \& Steinber, 2004; Loukas \& Robinson, 2004; LaRusso, Romer, \& Selman, 2008) linking student characteristics (i.e., age and ethnicity) as well as student perceptions of school climate to adolescent participation in risky behaviors. However, this study shows a lack of support for previous literature linking gender, socioeconomic status, and student performance in school to adolescent participation in risky behaviors. In this chapter I discuss the findings and conclusions drawn from the results of this study and provide a review of the limitations of this study and suggestions for future research. 
Student participation in risky behavior was investigated using middle and high school students' responses to 10 questions on the school district's Safe and Drug Free Schools Survey. This survey addresses substance use, safety concerns (i.e., feeling unsafe at school, outside the building, or on the way to or from school) and driving behavior. For the purpose of this study, items addressing risky behavior (i.e., substance use behavior such as frequency of use of alcohol, marijuana, other illegal drugs, and cigarettes) were analyzed. Prior research had suggested that student participation in risky behavior was linked to a number of student characteristics such as student age, ethnicity, gender, socioeconomic status, and performance in school (Arnett, 1999; Zuckerman, 2007; Cook, Buehler, \& Henson, 2009; Bryant \& Zimmerman, 2002).

Prior research also suggested that students' negative perceptions of school climate (which includes a student's sense of belonging and sense of connectedness with staff and peers) is linked to a student's participation in risky behaviors (LaRusso, Roemer, \& Selfman, 2008; Libbey, 2004; Harris, Duncan, \& Bojoisly, 2002). Research has shown school connectedness to be associated with lower levels of tobacco, marijuana, and alcohol use (Bonny et al., 2000). Data from this study show that as schools have a more positive perception of school climate they participate less in risky behaviors (alcohol, tobacco, and marijuana use).

Based on the literature, it was hypothesized in this study that student characteristics of age, gender, ethnicity, free/reduced lunch status, as well as, student perception of school climate and performance on standardized testing would predict student participation in risky behaviors. Given the anonymous nature of the data, it was necessary to examine the data at different levels. For some analyses, data were analyzed 
at the student level (for those variables that could be connected to the dependent variable at that level) and for others, data were analyzed at the school level (for those variables that could only be connected to the dependent variable at the school level); this resulted in two hypotheses.

First, it was hypothesized that student level gender, ethnicity, and age would significantly predict student participation in risky behaviors. Results of the data analysis did support this hypothesis. Analyses from this study replicated findings from previous research in that they indicated that males reported engaging more frequently in risky behaviors than females (Rudasill et al, 2010). However, while there is significance due to the large sample size, there is only a difference of .2 between the means for males (M $=36.21 ; \mathrm{SD}=6.53)$ and female $(\mathrm{M}=36.41 ; \mathrm{SD}=6.01)$. Despite what might be normally assumed, boys engage in more risky behaviors as compared to girls. this assumption is not adequate based on the current results.

Additional findings from this study replicate previous studies in that whites more frequently reported engaging in risky behaviors than racial and ethnic minorities which is contrary to popular assumptions. In fact, research shows that Caucasian youths' substance use rates have historically been approximately two times that of African American youths (Johnston et al., 2004). A study by Terry-McElrath, O’Malley, and Johnston (2009) supported the research showing that Caucasian youths endorsed more frequent substance use.

Additionally, this study assessed the motives behind the drug-using behavior and found that Caucasian users were more likely to report social/recreational reasons for use such as, "to have a good time", "to fit it", and "to experiment" while African American 
youths were more likely to report reasons such as "to get through the day". Finally, replicating previous studies, older adolescents (e.g., 19 year olds) more frequently reported engaging in risky behaviors than younger adolescents (e.g., 11 year olds).

It was also hypothesized that school level status (middle or high school), free/reduced lunch status, perception of school climate, and performance on standardized testing would significantly predict student participation in risky behaviors. Regarding this hypothesis, results were mixed. While the regression resulted in a significant linear relationship, only age was shown to be a significant predictor, accounting for $84.1 \%$ of the variance. Due to issues of multicollinearity resulting in a high correlation between the variables of performance on standardized testing and free/reduced lunch status, a second regression was conducted. Results from this regression showed a significant linear relationship in which school level status (middle or high) and perception of school climate were significant predictors of participation in risky behaviors.

Several possible explanations for the disparity between these results and the existing literature are possible. First, the sample in this study differs from the samples used in past studies, and some of the differences may have been significant. As previously stated, the second sample was taken from school level data; therefore, the results were comparisons of data from a sample of 42 schools as compared to evaluating the results of each individual student as has been done in prior studies. For example, Rudasill, Reio, Stipanovic, and Taylor (2010) demonstrate findings showing a significant relationship between gender, family income, and student-teacher relationships and risky behaviors at the individual level. The student level data in the present study, however, were aggregated to the school level to avoid an ecological fallacy. Second, regarding a 
lack of significance in the prediction of free/reduced price lunch status for participation in risky behaviors, the range of scores between school means was necessarily greatly reduced due to an intentional mixing of students from divergent backgrounds in each school. That is there is not much variability in the schools regarding free/reduced lunch status because a student from one area (e.g. a high poverty area) could be bused to a school that is in a traditionally affluent area and vice versa. Third, there was significant correlation between free/reduced price lunch status and standardized test scores when data were aggregated to the school level for analysis. Once school-level standardized test scores were removed from the equation school level status and school climate were found to be significant predictors of risky behaviors, accounting for $83.5 \%$ of the variance. This supports previous literature (Gardner \& Steinberg, 2005; Arnett, 1999) and shows that older adolescents (i.e, high school students) report engaging in risky behavior more frequently than younger adolescents (middle school students). These later analyses show that middle school students report both more positive perceptions of school climate and less frequent participation in risky behaviors.

Lastly, regarding gender differences, this study's findings differ from the majority of past research in which males more frequently reported engaging in deviant behavior (specifically alcohol, tobacco, and other drug use). However, results from a study conducted by Poulin, Hand, Boudreau, and Santor (2005) had found that females were more likely than males to report having consumed alcohol in the absence of heavy episodic drinking whereas the prevalence of heavy episodic drinking did not differ significantly in terms of gender. The Poulin et al. study (2005) also evaluated the level of depression of the adolescents and found that depression was more prevalent in female 
adolescents than male adolescents and that increasing levels of problematic alcohol use were associated with an increasing probability of depressive disorder.

\section{Study Limitations}

A number of limitations in this study should be noted. First, there was little variation in the student perceptions of school climate and risky behavior. Students in this sample had relatively high/positive perceptions of school climate and reported engaging in risky behaviors relatively rarely. For example the range of answers given on the school climate scale was 27.63 to 37.63 with higher numbers indicating a more positive school climate. The range of answers given on the risky behavior scale was from 32.24 to 39.50 with a maximum of 40.0 (indicating no participation in deviant behaviors).

Second, the sample size used to analyze school level data was relatively small with only 42 schools represented in the sample. Additionally, since the study took place at school during class time, with teachers present, the environment may have engendered feelings of discomfort, even though a commitment to anonymity was made to the respondents. Finally, since the measure of risky behaviors was based on self-report, the extent to which scores reflected actual behavior can only be presumed.

\section{Implications for Practice}

This study complements past research in informing schools on the value of promoting a positive school climate. Furthermore, this study helps alert teachers to the risky behaviors that adolescents are participating in, specifically the use of alcohol and other drugs, and the impact that fostering a positive school climate has on it. Congruent with the bioecological model (Bronfenbrenner, 1979), social learning theory (Bandura, 1977), and social control theory (Hirschi, 1969) results reported here support the 
importance of considering not only individual characteristics but how those individual characteristics interact with an individual's environment (in this case, the school environment) to contribute to the development of deviant behavior. School climate is a construct which encompasses different aspects of a student's experience in school such as one's sense of belonging to the school, satisfaction, teacher-student relationships, and quality of peer relationships and this study highlights the importance of focusing on those aspects to achieve more positive outcomes for the student.

This study joins past research in informing society of the increase in participation in risky behaviors as the individual navigates through adolescence (Rudasill et al., 2010; Cook, Buehler, \& Henson, 2009; Coker \& Borders, 2001; Arnett, 1999). This research demonstrates that as a student gets older his/her participation in risky behaviors increases. This study, in conjunction with past research, can help guide the implementation of prevention programs at the appropriate stage in development to help inhibit the initiation of risky behaviors. Additionally, it can help guide the implementation of intervention programs to address risky behaviors that are already prevalent in high schools.

Specifically, the transition from middle to high school has been suggested to be a very difficult transition for students (Voisin, 2006). This transition can lead to poor academic performance, self image, perceived social support, and perception of the quality of school life (Loukas \& Robinson, 2004). The students, in fact, typically report a decrease in their connectedness with teachers. The literature, however, suggests that adolescents' positive relationships with teachers are connected to a range of healthy outcomes, such as prosocial behavior, engagement in school, and belongingness to school 
(Wentzel, 2002); and low levels of connectedness with teachers are associated with reports of more risky behaviors (Voisin, 2006).

As is suggested by this study, positive school climate is seen as a protective factor (i.e., those factors that reduce the likelihood of problem behaviors) in that it is linked to less participation in risky behaviors. In conjunction with results showing a significant difference in the participation in risky behaviors from middle to high school (high schools showing more frequent risky behaviors) the need for prevention programs starting in middle school as well as more focus on the quality of the school climate during the transition from one school to the other is evident.

As previously stated, research has shown the importance of protective factors in playing a part to decrease students' participation in deviant behaviors such as substance use. Hirschi's Social Control theory (1969) further highlights the importance of bonding to the institution of school. In fact, this type of bonding, once strongly established, might serve as the mechanism by which deviant behavior is inhibited (Catalano, Haggerty, Oesterle, Fleming, \& Hawkings, 2004). Furthermore, strong school bonding has shown to be associated with less tobacco, alcohol, and drug use, and other delinquent behaviors (Catalano et al., 2004). With this said, in conjunction with the current findings showing that a positive perception of school climate has a positive relationship with less participation in risky behaviors an increase on the focus of school climate could help guide change in schools.

\section{Implications for Future Research}


To build upon the current findings, future research could focus on the many different aspects of school climate and how each of those aspects contributes to the participation in risky behavior. For example, encompassed in the variable of school climate are teacher-student relationships, sense of safety, quality of peer relationships, and feelings of belonging/connectedness. To pinpoint which of these aspects of school climate most significantly contribute to the participation in risky behavior could help more specifically guide interventions to promote change.

This study replicates prior research and heightens the focus on the increase in participation in risky behaviors as the adolescent progresses in age. There is a clear progression in the participation of risky behaviors from almost no endorsement of participation in risky behaviors at age 11 to significantly more participation as the student gets older, which is highlighted in this study. However, future research could focus on identifying the specific age at which an individual goes from no participation to significantly more will help in identifying the appropriate age to start intervening or implementing prevention programs to inhibit the behavior from progressing.

In addition to the findings of the relationship of school climate and participation in risky behaviors; future research should explore other educational outcomes as they relate to these variables. For example, school attendance, staying in school longer, and grades could be examined to evaluate their relationship to school climate and participation in risky behaviors. A longitudinal study could examine school climate as it relates to school attendance over time and ultimately staying in school longer. Additionally, grades could be evaluated over time to see how they relate to participation in risky behaviors and school climate measures. 
Prospective, experimental studies could explore whether interventions that promote more positive school climates cause adolescents to engage less frequently in risky behaviors. An experimental design in which an intervention targeted at promoting more positive school climates could be put in place and then evaluated to see if this caused a decrease/change in the resulting frequency of participation in deviant behaviors.

In addition to the findings of the current study in which an urban population was evaluated, future studies could evaluate individuals in different contexts (e.g. rural areas, small schools). Research consistently suggests that small high schools are in a better position than large schools to create a stronger sense of belonging (Cawelti, 1995; Ma, 2003). Additionally, research has suggested that attendance at small schools resulted in better student involvement, better interpersonal relationships, and easier management of individual and cooperative practices (Ma, 2003).

The research on emotional constructs as they relate to the participation in risky behaviors is limited. However, past research has shown associations with adolescents' risk-taking behaviors and depression (Poulin et al., 2005). Future studies could help to build upon the findings in the Poulin et al. (2005) study in which they found that depression is more prevalent in female adolescents than male adolescents and that increasing levels of problematic alcohol use are associated with an increasing probability of depressive disorder. Furthermore, future studies could implement intervention strategies such as individual therapy and evaluate if there is a decrease or change in the level of depression and hence the participation risk-taking behaviors such as alcohol use. 


\section{REFERENCES}

Akers, R.L. (1977). Deviant Behavior: A Social Learning Approach, $\left(2^{\text {nd }}\right.$ ed. $)$ Belmont, CA: Wadsworth Publishing.

Akers, R. L., Krohn, M. D., Lanza-Kaduce, L., \& Radosevich, M. (1979). Social learning and deviant behavior: A specific test of general theory. American Sociological Review, 44, 636-655.

Anderman, E. M. (2002). School effects on psychological outcomes during adolescence. Journal of Educational Psychology, 94, 795-809.

Anderson, E. (1999). Code of the street. New York, NY: Norton \& Company.

Ardelt, M., \& Day, L. (2002). Parents, siblings, and peers: Close social relationships and adolescent deviance. The Journal of Early Adolescence, 22, 310-349.

Arnett, J. (1999). Adolescent storm \& stress, reconsidered. American Psychologist $54(5), 317-326$.

Arnett, J. (1992). Reckless behavior in adolescence: A developmental perspective. Developmental Review, 12, 339-373.

Arthur, M. W., Hawkins, J. D., Pollard, J. A., Catalano, R. F., \& Baglioni, A. J. (2002). Measuring risk and protective factors for substance use, delinquency, and other adolescent problem behavior: The Communities that Care Youth Survey. 26(6) $575-601$.

Bandura, A. (1977). Social learning theory. Englewood Hills, NJ: Prentice-Hall. 
Bandura, A. (1982). Self-efficacy mechanism in human agency. American Psychologist, 37, 122-47.

Bandura, A. (1986) Social Foundations of Thought and Action: A Social Cognitive Theory. New York: Prentice-Hall.

Beam, M.R., Gil-Rivas, V., Greenberger, E., Chen, C. (2002). Adolescent problem behavior and depressed mood: risk and protection within and across social contexts. Journal of Youth and Adolescence, 31, 343-357.

Beinart, S., Anderson, B., Lee, S., Utting, D. (2002) Youth at Risk: A National Survey of Risk Factors, Protective Factors and Problem Behaviour among Young People in England, Scotland and Wales. London: Communities that Care.

Best, D., Manning, V., Gossop, M., Gross, S., \& Strong, J. (2006). Excessive drinking and other problem behaviors among 14-16 year old schoolchildren. Addictive Behaviors, 31(8), 1424-1435.

Blum, R. W., Beuhring, T., Shew, M. L., Bearinger, L. H., Sieving, R. E., \& Resnick, M. D. (2000). The effects of race/ethnicity, income, and family structure on adolescent risk behaviors. American Journal of Public Health, 90, 1879-1884.

Blum, R. W., \& Reinhart, P. M. (1996). Reducing the risk: Connections that make a difference in the lives of youth. Minneapolis: Division of General Pediatrics and Adolescent Health, University of Minnesota.

Bonny, A. E., Britto, M. T., Klosterman, B. K., Hornung, R. W., \& Slap, G. B. (2000). School disconnectedness: Identifying adolescent risk. Pediatrics, 106(5), $1077-1021$. 
Bronfenbrenner, U. (1977). Toward an experimental ecology of human development. American Psychologist, 7, 513-531.

Bronfenbrenner, U. (1979). The ecology of human development: Experiments by nature and design. Cambridge, MA: Harvard University Press.

Bronfenbrenner, U. (1989). Ecological systems theory. Annals of Child Development, 6, 187-249.

Bryant, A. L., \& Zimmerman, M. A. (2002). Examining the effects of academic beliefs and behaviors on changes in substance use among urban adolescents. Journal of Educational Psychology, 94(3), 621-637.

Burton, J. M. \& Marshall, L.A. (2005). Protective factors for youth considered at risk of criminal behavior: Does participation in extracurricular activities help? Criminal Behavior \& Mental Health, 15(1), 46-64.

Bussey, K. \& Bandura, A. (1999). Social cognitive theory of gender development and differentiation. Psychology Review, 106(4), 676-713.

Capaldi, D. M., Dishion, T. J., Stoolmiller, M., \& Yoerger, K. (2001). Aggression toward female partners by at-risk men: The contribution of male adolescent friendships. Developmental Psychology, 37, 61-73.

Catalano, R. R, Kosterman, R., Hawkins, J. D., Newcomb, M. D., \& Abbott, R. D. (1996). Modeling the etiology of adolescent substance use: A test of the social development model. Journal of Drug Issues, 26, 429-455.

Catalano, R. F., Haggery, K. P., Oesterle, S., Fleming, C. B., \& Hawkins, J. D. (2004). The importance of bonding to school for healthy development: Findings from the social development research group. Journal of School Health, 74(7), 252-261. 
Cawelti, G. (1995). The missing focus of high school restructuring. School Administrator, 52(11), 12-16.

Centers for Disease Control and Prevention. School Connectedness: Strategies for Increasing Protective Factors Among Youth.Atlanta, GA:U.S. Department of Health and Human Services; 2009.

Chassin, L., Tetzloff, C., \& Hershey, M. (1985). Self-image \& social-image factors in adolescent alcohol use. Journal of Studies on Alcohol, 46(1), 39-47.

Coker, J. K., \& Borders, L. D. (2001). An analysis of environmental and social factors affecting adolescent problem drinking. Journal of Counseling \& Development, 79, $200-208$.

Cook, E. C., Buehler, C., \& Henson, R. (2009). Parents and peers as social influences to deter antisocial behavior. Journal of Youth \& Adolescence, 38(9), 1240-1252,

Dishion, T. J., Capaldi, D. M., Spracklen, K. M., \& Li, F. (1995). Peer ecology of male adolescent drug use. Development and Psychopathology, 7, 803-824.

Dornbusch, S. M., Erickson, K. G., Laird, J., \& Wong, C. (2001). The relation of family and school attachment to adolescent deviance in diverse groups and communities. Journal of Adolescent Research, 16(4), 396-422.

Dowdell, E. B. (2006). Alcohol use, smoking, and feeling unsafe: Health risk behaviors of two urban seventh grade classes. Issues in Comprehensive Pediatric Nursing, $29,157-171$.

Duncan, S.C., Duncan, T.E., Strycker, L.A., \& Chaumeton, N.R. (2002). Relations between youth antisocial and prosocial activities. Journal of Behavioral Medicine, 25(5), 425-438. 
Edwards, D. (1995). The school counselor's role in helping teachers and students. Elementary School Guidance \& Counseling, 29, 191-197.

Elander, J., West, R., \& French, D. (1993). Behavioral correlates of individual differences in road-traffic crash risk: An examination of methods and findings. Psychological Bulletin, 13, 279-89.

Elkind, D. (1985). Cognitive development and adolescent disabilities. Journal of Adolescent Health Care, 6(2), 84-89.

Ennett, S. T., Foshee, V. A., Vangie A., Bauman, K. E., Hussong, A., Cai, L., Lus, H., Reyes, M., Faris, R., Hipp, J., Durant, R. (2008). The social ecology of adolescent alcohol misuse. Child Development, 79(6), 1777-1791.

Farrington, D. P. (1986). Age and crime. In M. Tonry \& N. Morris (Eds.), Crime and justice (pp. 29-90). Chicago: University Chicago Press.

Felson, R. B. \& Staff, J. (2006). Explaining the academic performance-delinquency relationship. Criminology, 44(2), 299-319.

Ferguson, Y. O., \& Ferguson, S. L. (2000). The impact of smoking on children's health: new initiatives. Journal of Pediatric Nursing, 15(6), 388-490.

Fine, M. (1991). Framing dropouts. Albany, NY: SUNY Press.

Fisher, I.A. \& Bauman, K.E. (1988). Influence and selection in the friend-adolescent relationship: findings from studies of adolescent smoking and drinking. Journal of Applied Social Psychology, 18, 289-314.

Flay, B., Hu, F., Siddiqui, O., Day, L. E., Hedeker, D., Petraitis, J., Richardson, J. \& Sussman, S. (1994). Differential influence of parental smoking and friends' smoking. Journal of Health \& Social Behavior, 35(3), 248-266. 
Fritz, D. J. (2000). Adolescent smoking cessation: How effective have we been? Journal of Pediatric Nursing, 15(5), 299-306.

Gardner, M. \& Steinberg, L. (2005). Peer influence on risk taking, risk preference, and risky decision making in adolescence and adulthood: An experimental study. Developmental Psychology, 41(4), 625-635.

Gerra, G., Zaimovic, A., Rizzi, O., Timpano, M., Zambelli, U., \& Ventimiglia, C. (1999). Substance abuse among secondary-school students and its relationship with social coping and temperament. Bulletin on Narcotics, L1V(1). 75-96.

Godly, S. H. (2006). Substance use, academic performance and the village school. Addiction, 101(12), 1685-1688.

Goff, B. G. \& Goddard, H. N. (1999). Terminal core values associated with adolescent problem behavior. Adolescence, 34, 47-60.

Gomberg, E. (1982). Historical and political perspective: women and drug use. Journal of Adolescent Health Care, 6(2), 84-89.

Gottfredson, G. \& Hirschi, T. (1990). A general theory of crime. Stanford, CA: Stanford University Press.

Gottfredson, G. D., Gottfredson, D. C., Payne A. A., \& Gottfredson, N. C. (2005). School climate predictors of school disorder: Results from a national study of delinquency prevention in schools. Journal of Research in Crime and Delinquency, 42(4), 412-444.

Gregersen, P., \& Bjurulf, P. (1996). Young novice drivers: Towards a model of their accident involvement. Accident Analysis \& Prevention, 28, 229-241. 
Hawkins, J. D., Catalano, R. K, \& Miller J. Y. (1992). Risk and protective factors for alcohol and other drug problems in adolescence and early adulthood: Implications for substance abuse prevention. Psychological Bulletin, 112, 64-105.

Hawkins, J. D., Catalano, R. F., Kosterman, R., Abbott, R., \& Hill, K. G. (1999). Preventing adolescent health-risk behaviors by strengthening protection during childhood. Archives of Pediatrics and Adolescent Medicine, 13, 226-234.

Harris, K. M., Duncan, G. J., \& Boisjoly, J. (2002). Evaluating the role of "nothing to lose" attitudes on risky behavior in adolescence. Social Forces, 80(3), 10051039.

Heimer, K. (1996). Gender, interaction, and delinquency: Testing a theory of differential social control. Social Psychology Quarterly, 59, 39-61.

Henry, K. L. \& Slater, M. D. (2002). The contextual effect of school attachment on young adolescents' alcohol use. Journal of School Health, 77(2), 67-74.

Hirschi, T. (1969). Causes of delinquency. Berkeley, CA: University of California Press.

Hirschi, T. (2002). Craft of Criminology: selected papers/Travis Hirschi. Ed. John H. Laub. New Brunswick, US: Transaction Publishers.

Jessor, R \& Jessor, S.L. (1977). Problem behavior and adolescent problem drinking. Academic Press.

Jessor, R. (1987). Risky driving and adolescent problem behavior: An extension of problem-behavior theory. Alcohol, Drugs and Driving, 3, 1-11.

Jessor, R., Turbin, M. S., \& Costa, F. M. (1997). Predicting developmental change in risky driving: The transition to young adulthood. Applied Developmental Science, 1, 4-16. 
Johnston, L. D, O'Malley, P M., Bachman, J. G., \& Schulenberg, J. E. (2004). Monitoring the future national results on adolescent drug use: Overview of key findings, 2003(NIH Publication No. 04-5506). Bethesda, MD: National Institute on Drug Abuse.

Jonah, B. A. (1986). Accident risk and risk-taking behavior among young drivers. Accident Analysis \& Prevention, 18, 255-271.

Jonah, B. A. (1990). Age differences in risky driving. Health Education Research, 5, 139-149.

Kaufmann, D. R., Wyman, P. A., Forbes-Jones, E. L., \& Barry, J. (2007). Prosocial involvement and antisocial peer affiliations as predictors of behavior problems in urban adolescents: Main effects and moderating effects. Journal of Community Psychology, 35(4), 417-434.

Kester, V. M. (1994). Factors that affect African-American students' bonding to middle school. Elementary School Journal, 95, 63-73.

Kipke M, ed. Risks and Opportunities: Synthesis of Studies on Adolescence. Washington, DC: National Academies Press; 1999.

Kobus, K. (2003). Peer and adolescent smoking. Addiction, 98, 37-55.

Kumpfer, K. L., \& Turner, C. W. (1991). The social ecology model of adolescent substance abuse: Implications for prevention. The International Journal of the Addictions, 25, 435-463.

Kuperminc, G. P., Leadbeater, B. J., Emmons, C., \& Blatt, S. J. (1997). Perceived school climate and difficulties in the social adjustment of middle school students. Applied Developmental Science, 1, 76-88. 
Kumar, R., O’Malley, P. M., Johnston, L. D., Schulenberg, J. E., \& Bachman, J. G. (2002). Effects of school-level norms on student substance use. Prevention Science, 3(2), 105-124.

Kuperminc, G. P., Leadbeater, B. J. \& Blatt, S. J. (2001). School social climate and individual differences in vulnerability to psychopathology among middle school students. Journal of School Psychology, 39, 141-159.

Larson, R., \& Richards, M. H. (1991). Daily companionship in late childhood and early adolescence: Changing developmental contexts. Child Development, 62, 284 300.

LaRusso, M. D., Romer, D., \& Selman, R. L. (2008). Teachers as builders of respectful school climates: Implications for adolescent drug use norms and depressive symptoms in high school. Journal of Youth \& Adolescence, 37(4), 386-398.

Libbey, H. P. (2004). Measuring student relationships to school: Attachment, bonding, connectedness, and engagement. Journal of School Health, 74(7), 274-283.

Loeber, R., \& Hay, D. (1997). Key issues in the development of aggression and violence from childhood to early adulthood. Annual Review of Psychology, 48, 371-410.

Losel, F. (1994). Protective effects of social resources in adolescents at high risk for antisocial behavior. In Weitekamp, E.G., Kerner, H.J., (eds.) Cross-national Longitudinal Research on Human Development and Criminal Behavior. London: Kluwer, 281-301.

Loukas, A. \& Robinson, S. (2004). Examining the moderating role of perceived school climate in early adolescent adjustment. Journal of Research on Adolescence $14(2), 209-233$. 
Lynskey, M. T., Fergusson, D. M., \& Horwood, W. (1998). The origins of the correlation between tobacco, alcohol, and cannabis use during adolescence. Journal of Child Psychology \& Psychiatry \& Allied Disciplines, 39, 995-1005.

Ma, X. (2003). Sense of belonging to school: Can schools make a difference? Journal of Educational Research, 96(6), 340-349.

Maddox, S. J., \& Prinz, R. J. (2003). School bonding in children and adolescents: Conceptualization, assessment, and associated variables. Clinical Child and Family Psychology Review, 6(1), 31-49.

Marshal, M. P. \& Chassin, L. (2000). Peer influence on adolescent alcohol use: The moderating role of parental support and discipline. Applied Developmental Science, 4, 80-88.

McNeely C. (2003). Connections to school as an indicator of positive development. Paper presented at the Indicators of Positive Development Conference, Washington, DC.

McLoyd, V. (1990). The impact of economic hardship on black families and children: Psychological distress, parenting, and socioemotional development. Child Development, 61, 311-346.

Morrongiello, B. A. \& Dawber, T. (2000). Mothers' responses to sons and daughters engaging in injury-risk behaviors on a playground: Implications for sex differences in injury rates. Journal of Experimental Child Psychology, 76(2), 89103. 
National Highway Traffic Safety Association, Traffic safety facts (2004) A compilation of motor vehicle crash data from the Fatality Analysis Reporting System and the General Estimates System. Washington, D.C.:NHTSA, US DOT Publication Vol. DOT HS 809919

Nucci, L. P., Guerra, N., \& Lee, J. (1991). Adolescent judgments of their personal, prudential, and normative aspects of drug usage. Developmental Psychology, 27, 841-848.

Pardini, D. A., Loeber, R., \& Stouthamer-Loeber, M. (2005). Developmental shifts in parent and peer influences on boys' beliefs about delinquent behavior. Journal of Research on Adolescence, 15(3), 299-323.

Patterson, G. R., Dishion, T. J., \& Yoerger, K. (2000). Adolescent growth in new forms of problem behavior: Macro- and micro-peer dynamics. Prevention Science, 1, 313.

Petraitis, J., Flay, B. R., \& Miller, T. Q. (1995). Reviewing theories of adolescent substance use: Organizing pieces in the puzzle. Psychological Bulletin, 117, 6786.

Poulin, C., Hand, D., Boudreau, B., \& Santor, D. (2005). Gender differences in the association between substance use and elevated depressive symptoms in a general adolescent population. Addiction, 100(4), 525-535.

Prinstein, M. J., Boergers, J., \& Spirito, A. (2001). Adolescents' and their friends' health-risk behavior: Factors that alter or add to peer influence. Journal of Pediatric Psychology, 26(5), 287-198. 
Preusser, D. F., Ferguson, S. A., \& Williams, A. F. (1998). The effect of teenage passengers on the fatal crash risk of teenage drivers. Accident Analysis \& Prevention, 30, 217-222.

Resnick, M.D., Harris, L.J., Blum, R.W. (1993). The impact of caring and connectedness on adolescent health and well-being. Journal of Pediatrics \& Child Health 29:S39.

Resnick, M.D., Bearman, P.S., Blum, R.W., (1997). Protecting adolescents from harm. Findings from the National Longitudinal Study on Adolescent Health. JAMA; 278(10):823-832.

Resnick, M. D., Bearman, P. S., Blum, R. W, Bauman, K. E., Harris, K. M., Jones, J., Tabor, J., Beuhring, T., Sieving, R. E., Shew, M., Ireland, M., Bearinger, L. H., \& Udry, J. R. (1997). Protecting adolescents from harm: Findings from the National Longitudinal Study on Adolescent Health. Journal of the American Medical Association, 278, 823-832.

Robbins, C. \& Martin, S. (1993). Gender, styles of deviance, and drinking problems. Journal of Health \& Social Behavior, 34(4), 302-321.

Roeser, R. W., \& Eccles, J. S. (1998). Adolescents' perceptions of middle school: Relation to longitudinal changes in academic and psychological adjustment. Journal of Research on Adolescence, 8(1), 123-158.

Rudasill, K.M., Reio, T.G., Stipanovic, N., \& Taylor, J.E. (2010). A longitudinal study of student-teacher relationship quality, difficult temperament, and risky behavior from childhood to early adolescence. Journal of School Psychology, 48(5), 389412. 
Samdal, O., Wold, B., Klepp, K. I., \& Kannas, L. (2000). Students' perceptions of school and their smoking and alcohol use: A cross-national study. Addiction Research, $8(2), 141-167$.

Sarkar, S. \& Andreas, M. (2004). Acceptance of and engagement in risk driving behaviors by teenagers. Adolescence, 39(156), 687-700.

Simons-Morton, B., Lerner, N., \& Stinger, J. (2005). The observed effects of teenage passengers on the risky driving behavior of teenage drivers. Accident Analysis \& Prevention, 37, 973-982.

Steinberg, L. (2004). Risk taking in adolescence: What changes, and why? Annals of the NewYork Academy of Sciences, 1021, 51-58.

Steinberg, L. \& Morris, A. S. (2001). Adolescent development. Annual Review of Psychology, 52, 83-110.

Stockard, J., \& Mayberry, M. (1992). Effective educational environments. Newbury Park, CA: Corwin.

Substance Abuse and Mental Health Services Administration. (2003). Results from the 2002 National Survey on Drug Use and Health: National Findings, Rockville, MD : Office of Applied Studies, NHSDA Series H-22, DHHS Publication Vol. SMA 03-3836.

Sutherland, E.H. \& Cressey, D.R. (1966). Principles of Criminology. Philadelphia: Lippicott.

Terry-McElrath, Y.M., O’Malley, P.M., \& Johnston, L.D. (2009). Reasons for drug use among American youth by consumption level, gender, and race/ethnicity: 1976-2005. Journal of Drug Issues, 39(3), 677-713. 
U.S. Department of Health and Human Services (2000). 10th Special Report to the U.S. Congress on Alcohol and Health, Author, Washington, DC. Retrieved from http://www.niaaa.nih.gov/Pages/default.aspx

Verdurmen, J., Monshouwer, K., VanDorsselaer, S., TerBogt, T., \& Vollerbergh, W. (2005). Alcohol use and mental health in adolescents: Interactions with age and gender -- findings from the Dutch 2001 Health Behavior in School-aged Children Survey. Journal of Studies on Alcohol, 66(5), 605-609.

Vitaro, F., Brendgen, M., \&Tremblay, R. E. (2000). Influence of deviant friends on delinquency: Searching for moderator variables. Journal of Abnormal Child Psychology, 28, 313-325.

Voisin, D. \& Neilands, T. (2010). Low school engagement and sexual behaviors among African American youth: Examining the influences of gender, peer norms and and gang involvement. Children \& Youth Services Review, 32(1), 51-57.

Weishew, N. L., \& Peng, S. (1993). Variables predicting students' problem behaviors. Journal of Educational Research, 87, 5-17.

Werner, E. E., \& Smith, R. S. (1992). Overcoming the odds: High risk children from birth to adulthood. Ithaca, NY: Cornell University Press.

West, R. \& Hall, J. (1997). The role of personality and attitudes in traffic accident risk. International Association of Applied Psychology, 46, 253-264.

Zakrajsek, J.S. \& Shope, J.T. (2006). Longitudinal examination of underage drinking And subsequent drinking and risky driving. Journal of Safety Research, 37(5), $443-451$. 
Zhang, Q., Loeber, R., \& Stouthamer-Loeber, M. (1997). Developmental trends of delinquent attitudes and behaviors: Replications and synthesis across domains, time, and samples. Journal of Quantitative Criminology, 13, 181-215.

Zimring, F. E. (1998). American youth violence. Oxford, England: Oxford University Press.

Zuckerman, M. (2007). Sensation seeking and risky behavior. Washington, DC: American Psychological Association. 


\title{
CURRICULUM VITAE
}

\author{
Jessica Damron-Bell, M.S.
}

\author{
128 Camelot Court \\ Russell, KY 41169 \\ (859) 494-0195 \\ jdamronbell@radicalrehab.com
}

\section{EDUCATION}

Currently enrolled in University of Louisville, Ph.D. Program in Counseling Psychology. Dissertation Proposal Defended March 2011; APA-approved Predoctoral Internship completed August 2008; Comprehensive Examinations completed July 2006.

M.S: Clinical Psychology, Eastern Kentucky University, July 2004.

B.A: Psychology, University of Kentucky, May 2002

Attended: Centre College - Fall1998 - Spring 2000

\section{RELEVANT FIELD WORK \& INTERNSHIP POSITIONS}

Radical Rehab Solutions, L.L.C., Psyhcotherapist, May 2011 to Present. Duties: individual and group therapy with individuals with Traumatic Brain Injuries; psychoeducation groups; neuropsychological assessments. Clinical Supervisor: James Phifer, Ph.D.

Southern Ohio Behavioral Health, Mental Health Clinician, January 2010 to May 2011. Duties: individual therapy with adults, children, families, and nursing home population; psychological assessments. Administrative Supervisor: Wendy Blevins, Ph.D.

Kentucky River Community Care, Mental Health Clinician; Clinical Coordinator/Outreach Clinician for Rape Crisis Center, April 2009 to December 20009. Duties: individual therapy with adults, children, and families; intakes; psychological assessments. Clinical Coordinator and Outreach clinician position, under VOCA (Victims of Crime Act) grant, includes serving 4 counties within the 8 county region of KRCC, working with victims of sexual assault and their families. Clinical Supervisor: Vincent Dummer, Psy.D. 
Kentucky River Community Care, School Based Clinician, August 2008 to April 2009. Duties: individual and group therapy with children and adolescents in school setting; psychological assessments with childrenand adults in outpatient office. Supervisor: Vincent Dummer, Psy.D.; Administrative Supervisor: Charles Boggs.

East Kentucky Rural Predoctoral Internship Program, August 2007 to August 2008. Duties: individual therapy and psychological assessment in Community Mental Health outpatient setting with adults and children; individual and group therapy (focus on emotion regulation and drug and alcohol dependence), and psychological assessments in ARH psychiatric center; psychological evaluations for admission into psychiatric hospital. Supervisors: Vincent Dummer, Psy. D., Mark Phillips, Psy.D. and Amy Goodson, Ph.D.

Field Study, Frazier Rehabilitation Institute, July 2005 to May 2006. Duties: Neuropsychological assessments - administration and scoring, research of norms and standardization of tests used in the psychology lab. Supervisor: Catherine Frantom, Ph.D.

Practicum, The Morton Center, September 2004 to May 2005. Duties: chemical dependency assessments, co-leader of group therapy, participation in chemical dependency education classes, individual and family therapy. Supervisor: Bud Newman, Psy.D.

Internship, Neurobehavioral Services, PSC, Spring $2004 . \quad$ Duties: Psychological/Neuropsychological assessments, LD/ADHD assessments, intake interviews, writing of reports. Assessments are conducted in conjunction with the Department of Vocational Rehabilitation, Department of Disability Determination Services, Law Offices, and Associates in Neurology. Duties also include researching new/more appropriate assessment instruments for interest areas of the office and researching the most current norms for a number of tests. Supervisor: Timothy Carbary, Ph.D.

Practicum, Eastern Kentucky University Psychology Clinic, Fall 2002 - Fall 2003. Duties: individual therapy, group therapy, assessments, and psychological evaluations. Supervisors: Don Beal, Ph.D., Robert Brubaker, Ph.D., \& Myra Beth Bundy, Ph.D.

Practicum, Eastern Kentucky University Psychology Clinic, Fall 2003. Duties: conducting intakes; organizing social skills, anger management, and divorce groups for area elementary and middle schools; autism \& asperger assessments; individual therapy. Supervisor: Robert Brubaker, Ph.D. \& Myra Beth Bundy, Ph.D.

Children's Social Group, Eastern Kentucky University, Fall 2003. Duties: organizing and conducting of social group to encourage social interactions with a diverse population and to promote adaptive assertiveness skills. Supervisor: Myra Beth Bundy, Ph.D. 
Autism Social Group, Eastern Kentucky University, Summer 2003. Duties: encouraging appropriate social interactions and participation in group activities. Supervisor: Myra Beth Bundy, Ph.D.

Practicum, Estill County Therapeutic Rehabilitation Program, Spring 2003. Duties: coleader of weekly group therapy with clients; promoting interaction with clients; assisting with organization of group activities and outings. Supervisor: Joyce Morin-Smith, Ed.D.

Internship, Bluegrass Personal Care Home, Spring 2002. Duties: documentation of resident's weekly activities, participation in group therapy sessions, conducted a longitudinal report history of resident's progress from date of admission. Supervisor: Herbie Burke.

\section{$\underline{\text { Research Experience }}$}

Graduate Research Assistant, University of Louisville, Fall 2004 to June 2007. Supervisor: Robert Felner, Ph.D.

Research Assistant, Eastern Kentucky University, Summer 2003 \& Fall 2003. Duties: assisting with tracking and analysis of the graduate level Research in Education courses on-line and on-campus; literature reviews; maintaining the data base for the College of Education's assessment system (Including TracDat) and data input and analysis for grant projects relating to adult and K-12 Professional Educator training and education; assisting with development and maintenance of the Professional Education Units continuous Assessment Plan/System (PECAP), which guides the management and operation of the Professional Education program improvement system, vital to the daily and long range operation of the Unit. Supervisor: Paul Erickson, Ph.D.

Research Assistant, Eastern Kentucky University, Spring 2003. Duties: independent running of subjects; coding transcriptions \& video tape data. Supervisor: Robert Mitchell, Ph.D.

Research Assistant, studies on what one thinks about drinking alcohol and how that relates to how one feels about him or herself, Fall 2001. Duties: Independent administration of questionnaires to $1^{\text {st }}, 5^{\text {th }}$, and $8^{\text {th }}$ graders. Supervisor: Gregory T. Smith, Ph.D.

Research Assistant, studies on the role of media in development of expectancies for eating and dieting and thinness, Fall 2001. Duties: Independently administered questionnaires to students for research being conducted at the University of Kentucky. Supervisor: Gregory T. Smith, Ph.D. 


\section{HONORS AND AWARDS}

University Fellowship, Fall 2005 - June 2007, University of Louisville Grawmeyer Fellowship, Fall 2004 - Summer 2005, University of Louisville Graduated with honors, Magna Cum Laude - University of Kentucky University of Kentucky Dean's List, 2000-2002

RASP Scholarship, 1998-2000

Centre College Recognition Scholarship, 1998-2000

\section{PROFESSIONAL SOCIETIES}

American Psychological Association, Student Affiliate

\section{PRESENTATIONS}

Adams, R., Brittain, S., McCane, A., \& Damron-Bell, J. Preschool Attendance and the Development of Socio-Emotional Competencies in Hispanic Children. Poster presentation at American Psychological Association Conference, Fall 2006.

Damron, Jessica \& Beal, D.G. The Concurrent Validity of the Burns Depression Checklist-Revised using the Beck Depression Inventory-II and the Burns Depression Checklist, Spring 2004. Poster presented at the annual Spring Research Conference for the Universities of Louisville, Kentucky and Cincinnati, Spring 2005.

Damron, Jessica \& Beal, D.G. The Concurrent Validity of the Burns depression Checklist-Revised using the Beck Depression Inventory-II and the Burns Depression Checklist, Spring 2004. 